\title{
Differences in Quality Environmental Rating Subscales between Family Child Care Homes and Facilities in West Virginia
}

Kaitlin J. Buchanan

West Virginia University

Follow this and additional works at: https://researchrepository.wvu.edu/etd

\section{Recommended Citation}

Buchanan, Kaitlin J., "Differences in Quality Environmental Rating Subscales between Family Child Care Homes and Facilities in West Virginia" (2012). Graduate Theses, Dissertations, and Problem Reports. 873. https://researchrepository.wvu.edu/etd/873

This Thesis is protected by copyright and/or related rights. It has been brought to you by the The Research Repository @ WVU with permission from the rights-holder(s). You are free to use this Thesis in any way that is permitted by the copyright and related rights legislation that applies to your use. For other uses you must obtain permission from the rights-holder(s) directly, unless additional rights are indicated by a Creative Commons license in the record and/ or on the work itself. This Thesis has been accepted for inclusion in WVU Graduate Theses, Dissertations, and Problem Reports collection by an authorized administrator of The Research Repository @ WVU. For more information, please contact researchrepository@mail.wvu.edu. 
Differences in Quality Environmental Rating Subscales between Family Child Care Homes and Facilities in West Virginia

\author{
Kaitlin J. Buchanan \\ Thesis submitted to the \\ College of Human Resources and Education \\ at West Virginia University \\ in partial fulfillment of the requirements for the degree of \\ Master of Arts \\ in Educational Psychology \\ with an emphasis in Child Development and Family Studies \\ Barbara G. Warash, Ed. D., Chair \\ Reagan Curtis, Ph. D. \\ Suzanne Hartman, Ph.D. \\ Department of Technology, Learning, and Culture \\ Morgantown, West Virginia \\ 2012
}

Keywords: family child care; environmental rating scale; process quality; structural quality Copyright 2012 Kaitlin J. Buchanan 


\begin{abstract}
Differences in Quality Environmental Rating Subscales between Family Child Care Homes and Facilities in West Virginia

Kaitlin J. Buchanan

Quality of family child care homes and facilities in the state of West Virginia was investigated for differences in quality and provider education and training. Data was collected through the West Virginia Department of Health and Human Resources grant titled, "Quality Rating and Improvement for West Virginia Child Care.” Quality was measured using the Family Child Care Environmental Rating Scale (FCCERS), which has 38 items across 7 subscales including aspects specific to the family child care setting. Twenty-nine family child care facilities and 55 family child care homes participated in the study. Family child care homes scored lower than facilities on all subscales of the FCCERS. Providers of family child care homes also had lower levels of education, which was related to quality of care across FCCERS subscales.
\end{abstract}




\section{Acknowledgment}

I would like to express my utmost gratitude to my advisor and committee chairperson, Dr. Barbara Warash. Her mentoring, encouragement, and guidance attributed to the completion of my Master's level research and education. Along with my committee chairperson, I would like to thank fellow committee members Dr. Reagan Curtis and Dr. Suzanne Hartman for their direction and assistance during the construction of my thesis. I owe special acknowledgement to Jay Slaughter for providing funding for my research through the Phyllis and Jay Slaughter Family Fellowship. Finally, I would like to thank my family and friends who have continuously offered support throughout my educational and life journey. 


\section{Table of Contents}

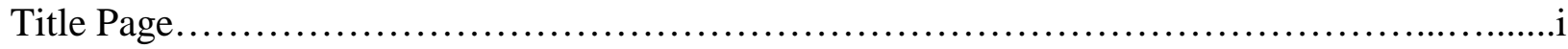

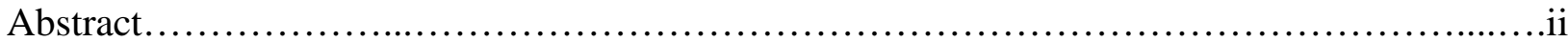

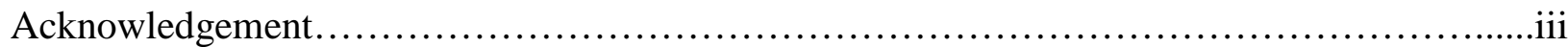

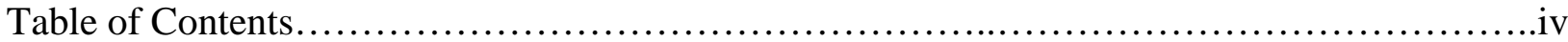

\section{CHAPTER I}

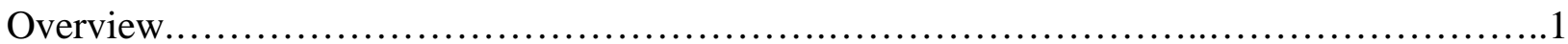

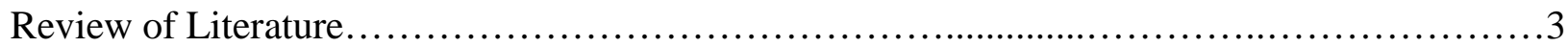

Federal \& State Regulations/Policies............................................5

Factors that Influence Quality...................................................

Aspects of Process Quality...............................................9

Subscales of the FCCERS ............................................10

Space \& Furnishings........................................11

Personal Care Routines.........................................12

Listening \& Talking.......................................14

Activities......................................................14

Interaction................................................. 15

Program Structure.........................................18

Parents \& Provider..........................................19

Aspects of Structural Quality............................................19

Effects of Structural Quality on Process Quality..............................20

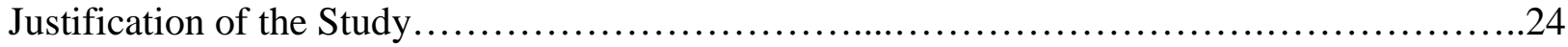

\section{CHAPTER II}

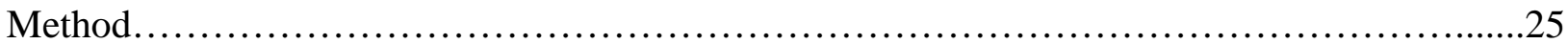

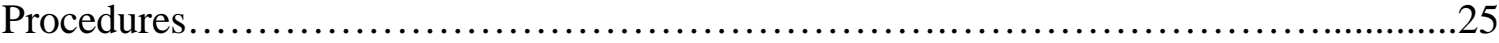

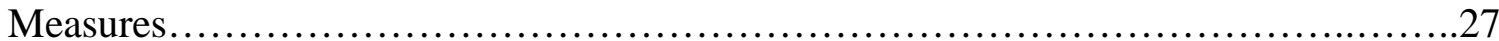

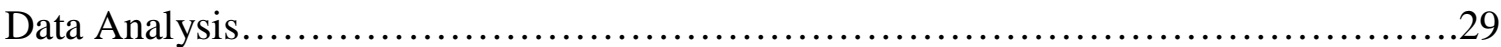

\section{CHAPTER III}

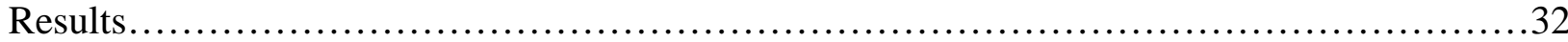

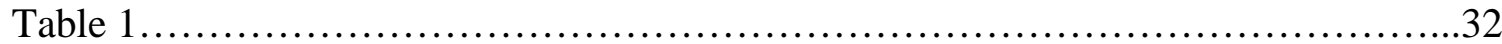

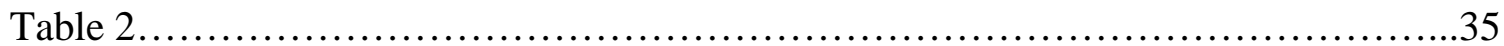

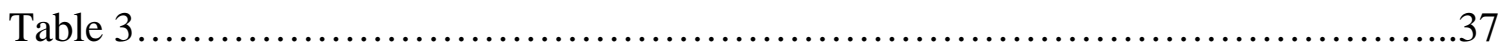

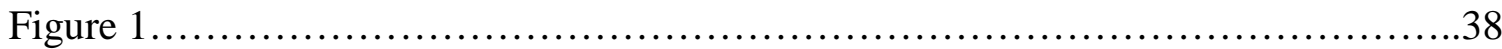

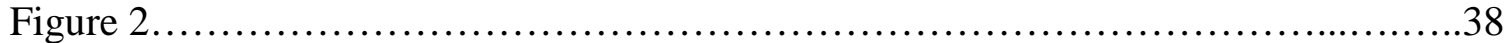

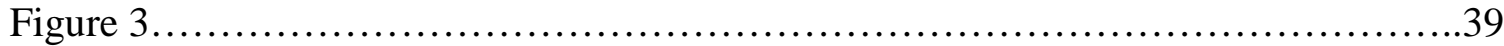

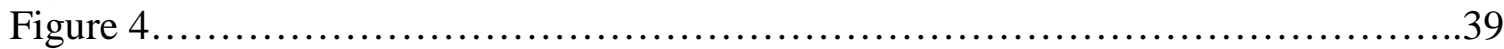

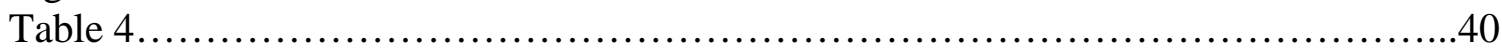

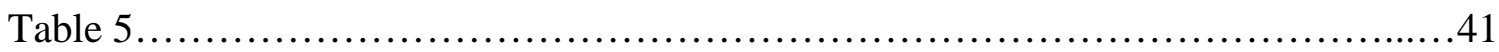




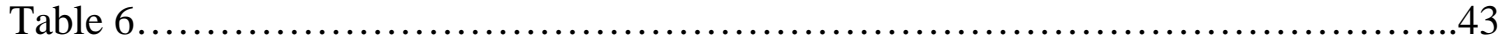

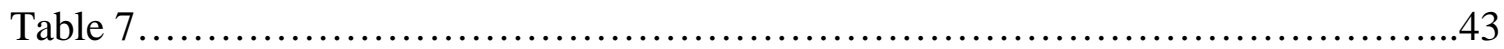

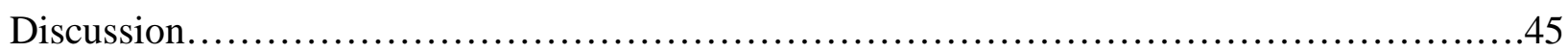

Future Research \& Limitations..................................................49

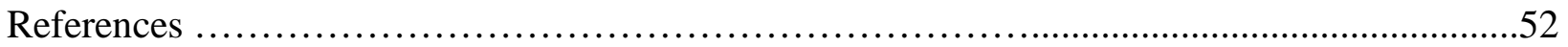

Appendix: Anecdotal Notes.......................................................57 


\section{Chapter I}

\section{Overview}

"Research confirms what most people intuitively know: Quality child care that encompasses strong developmental experiences has a long-term positive impact on academic achievement and provides important social benefits for vulnerable children at risk of poor outcomes. For lots of kids, these early formed benefits extend through adolescence and into adulthood” (Annie E. Casey Foundation, 2006, p. 4).

Many social problems in our society can be avoided if investments are made in children's early years. Quality early education programs are beneficial to children and to the society at large. A study by the Partnership for America’s Economic Success (2011) showed that children attending preschool showed greater likelihood of graduating high school and less criminal activity. This alludes to the benefits of child care centers, but what about family child care? As of 2005, over 60 percent of children under five have attended some type of non-parental child care regularly. The majority of them have mothers who work outside the home. Mothers who work longer hours have been found to use family child care homes of lower quality (Fuller, Kagan, Loeb, \& Chang, 2004). One in 10 families with employed mothers use family child care as primary care while others use it as secondary care. Family child care has been increasingly utilized in recent years with nearly one in four children spending over 30 hours a week in family child care. Trends in families who use family child care show that family child care is preferred for infants and toddlers, that single women use the service, and that families with low-income use unregulated, family child care homes.

In 2007, there were 213,966 licensed family child care homes in the United States with the majority being small family child care homes caring for up to six children and about $20 \%$ 
being large family child care homes caring for up to 12 with the help of an assistant to the provider (Morrissey, 2007). According to the Annie E. Casey Foundation (2006), 2.3 million people care for children five years of age or younger every week and are paid to do so, onefourth of whom provide home-based care. The low adult-child ratios, home-like environment, convenience, and cost are factors toward families’ preference for home-based care.

The current study investigated the quality of family child care homes and facilities in West Virginia according to West Virginia's licensing regulations and the subscale scores of the Family Child Care Environmental Rating Scale (FCCERS). Quality differences based on the subscales of the FCCERS were examined, as well as the educational and training levels of the child care providers, which included director and teacher. The following research questions guided the study: 1) Do FCCERS subscale scores differ between family child care homes and family child care facilities? 2) Does provider's level of education differ by type of family child care? 3) How do subscale scores relate to provider's level of education? 


\section{Review of Literature}

Family child care is a major source of child care in the United States for working parents with young children (Bordin, Machida, \& Varnell, 2000). Many parents prefer family child care because of its convenience of location in neighborhoods, lower rates, individualized attention, and more flexible hours, which include night and weekend hours (Fuller et al., 2004; Lanigan, 2011). Family child care providers, mostly mothers, also reap benefits by collecting income while caring for their own children at the same time, which one-third of providers manage (Walker, 2002).

Transversely, research has found negative effects of family child care for providers and families. The low earnings and long hours of work with scarce benefits cause a high turnover rate (Walker, 2002). Turnover rates have negative effects on the quality of care by adding to adjustment problems in children and creating less assurance and more anxiety for families (Morrissey, 2007). Another reason for turnover in family child care providers is the stress of role overload between work and family (Walker, 2002). Still others become socially isolated due to the adult-child ratio often times being one to six in a small family child care home with no other adults present (Lanigan, 2011). The high turnover rates make it difficult to keep accurate records of operating family child care homes and facilities, as there is not even a universal definition.

Due to the vast array of licensing regulations in the United States, it is difficult to obtain a clear picture of the family child care landscape. Defining the terminology and levels of care associated with family child care presents additional problems as they vary between states. There is no universal definition of family child care, nor distinctions of family child care programs or quality among them. "There is little existing research that has examined the effects 
of the growing number of policies aimed at promoting quality in family child care, including quality rating scales” (Morrissey, 2007, p. 19).

In general terms, family child care is home-based care that is an owner-operated small business, typically containing mixed-age groups and siblings. It can be regulated or unregulated. Ten states do not have any type of regulations for home-based care (Morrissey, 2007). For the purpose of this study, family child care is delineated as either family child care homes or family child care facilities (West Virginia Department of Health \& Human Resources, 2007). In West Virginia, a family child care home is defined as a child care in the provider's home with no more than six children under 13 years of age and no more than two children under the age of 24 months. A family child care facility is defined as a child care that must have two staff present if there are more than six children under 13 years of age or more than two children under the age of 24 months. A family child care facility can be located in the provider's residence or a separate building.

Also according to the 2007 licensing requirements of the West Virginia Department of Health and Human Resources (WVDHHR), family child care is home-based care provided up to 18 hours in a 24 hour period in a private family home of the provider for compensation. This type of child care does not need to be regulated if the provider is caring for less than four unrelated children. If a provider is caring for less than four children or relatives they are known as an informal family child care. In order to be approved for funding at least one of three children must be a non-relative of the provider and the provider must be requesting reimbursement for one child.

A registered family child care home provides child care for compensation in the provider's home. A registered family child care home may serve four to six children less than six 
years of age. These children may include children living in the provider's home and cannot include more than two children younger than 24-months in age. A family child care facility may serve seven to 12 children for four or more hours a day. The provider may care for no more than four children under the age of 24 months. Children under the age of six who reside in the provider's home may be included in the total number of children, not exceeding 12 . Care may be in the operator's home or in a facility that is not inhabited by the provider. Therefore, the primary differences between family child care homes and the facilities are the total number of children in care and the possibility of a location other than the provider's home being used. According to the National Child Care Information and Technical Assistance Center there are states that serve up to 16 children in a small family child care home and up to 20 in a large family child care home (West Virginia Department of Health \& Human Resources, 2007).

\section{Federal and State Regulations/Policies}

It is important to look at existing federal and state policies that attempt to control quality issues. The U.S. Department of Agriculture's (USDA) Child and Adult Food Program, Early Head Start, and the Child Care and Development Fund are federal programs designed to improve the quality of child care which includes services to family child care homes. Many licensed child cares, including those in West Virginia, adhere to these federal and state policies in order to qualify for funding. Many states have tiered reimbursements for reaching higher levels of quality above the basic licensing requirements (Morrissey, 2007). However, less than one-third of subsidies are used for family child care, and providers often do not apply for funding opportunities. It is very hard for these providers to improve their centers with necessary safety equipment, maintenance, and materials because of finances (Anne E. Casey Foundation, 2006). 
West Virginia is one of the states that provide a tiered subsidy program. Tier I child care programs receive the least amount of money and have minimum standards to meet. Tier II receives more funds by meeting additional standards. Tier III child care programs are nationally accredited and receive the most subsidy money (West Virginia Department of Health \& Human Resources, 2011). West Virginia has two Tier III homes, three facilities, and 26 centers. Instead of sinking funds into centers that are on their way to a Tier III, why not improve the quality of centers of poor quality? Raikes, Raikes, and Wilcox (2005) investigated the relationship between regulation, subsidy, and quality to find that more regulation and a lesser amount of children receiving subsidies, along with high levels of provider education and training provide a higher quality environment.

Universal Pre-K programs in 12 states, including West Virginia, allow family child care homes to provide Pre-K services (Morrissey, 2007). Although these lines of resources help to sustain some commonalties, many variations still exist. For example, in 2007 the National Child Care Information and Technical Assistance Center reported that only nine states require preservice training in small family child care homes, 12 states required training during the licensure period only, and 38 require ongoing training which ranged from zero to 45 hours (Lanigan, 2011).

In recent news, many states applied for the Federal Race to the Top grants, which were intended to increase the number of low-income and disadvantaged children enrolled in highquality programs and services. The purpose of the grant was to prepare children for later success by adopting standards, assessments, and data systems that will improve student achievement and teacher practices in hopes to improve schools with low achievement (Department of Education, 2011). West Virginia completed a Race to the Top proposal that focused on comprehensive 
services for young children as well as assisting early childhood educators to move through a progression of credentials. However, West Virginia was not one of the nine states awarded funding. In fact out of 35 states, the District of Columbia, and Puerto Rico, West Virginia was the $22^{\text {nd }}$ applicant in queue to receive grant money. Especially devastating to the application was a low score for the following selection criteria: promoting participation in tiered quality rating and improvement systems throughout the state.

As stated earlier, collecting comprehensive data on family child care is difficult because regulations of family child care vary greatly from state to state. Variations from licensing process requirements to adult-child ratios differ immensely along with minimum standards. This leads to another question: Are states complying with minimum standards for family child care? Is there a relationship between compliance and quality? Furthermore, regulating family child care is difficult because of high turnover, making these businesses hard to maintain. If providers do not comply with regulations they may stop serving children or continue to operate without notifying the system. States vary in frequency of family child care home inspection, if they are inspected at all. Often times because of the large number of family child cares, once registered family child care settings are not inspected for compliance unless there is a complaint to investigate. Noncompliance is found mostly in cases where the provider did not understand the standards (Wilkes, Lambert, \& VandeWiele, 1998). Grubb (1993) found that family child care home providers merely had to sign a statement to confirm that they were in compliance at the time of registration and yearly thereafter. For family child care homes with minimal certification and regulation requirements it is difficult to assess their quality and in turn difficult to maintain or improve quality as well. Often times they go unnoticed, making it nearly impossible to even know how many family child care homes are operating (Fiene, 1995.) 
Home-based care has become a common child care solution for children under age six whose families have inflexible work schedules at entry-level jobs in which they make low earnings. It makes sense that family child care providers be offered support. By providing family child care providers with resources to improve the quality of care it will help to increase physical, cognitive, and social development, which contributes to school readiness in children. Family child care providers are isolated from further trainings, which all are attributed to quality. Resources that could be offered include business advice, credentialing information, and safety, quality, and curriculum improvement ideas (Annie E. Casey Foundation, 2006). In a study by Wilkes and colleagues (1998), the following aspects of technical assistance were provided: health, supervision, safety, records, discipline, activities, equipment, nutrition, physical plant, reporting requirements, waivers, and other miscellaneous areas. The authors found that when technical assistance is included in inspections that compliance with standards increases. Through technical assistance it is possible for regulators to explain regulations to providers through discussion and clarification. Through this concept providers can learn about the basis for the rules and can be provided with assistance in meeting them (Wilkes et al., 1998).

\section{Factors that Influence Quality}

Quality of family child care homes and facilities is also difficult to measure and maintain due to the lack of unity and stringency on licensing and regulating policies. Structural quality and process quality are both important aspects of family child care. Structural quality refers to factors such as provider education, experience, knowledge, group size, and ratios whereas process quality refers to the daily experiences of children in family child care according to the provider's response to their needs. Process quality can be improved when structural quality is regulated and can be achieved through a nurturing provider (Bordin et al., 2000; Cryer, 1999). 
Aspects of process quality. Settings of the child care home environment affect interactions that take place and the development of children. Safety, health, and development should be focused on in the environment. Quality child care is defined as "care that ensures children's safety, promotes their health, and provides many age-appropriate play opportunities to enhance their development” (Harms, 1992, p. 171). Falls are the major cause of injury in children in child care homes, yet regulations vary on providing guidelines for prevention, such as height of equipment, ground surfaces, and clearance around equipment. Personal hygiene and sanitation are major health concerns in child care, especially because children in group care who are still in diapers are twice as likely to suffer from diarrhea (Harms, 1992). Children's hands and faucets are the most contaminated surfaces in a child care. Sanitation of diapering tables, sinks, and proper disposal of diapers can alleviate these problems. Hand washing before and after handling food helps in food preparation, but is surprisingly not performed as often as it should be (Harms, 1992).

Toddler environments require many aspects to be of high quality, namely safety and sanitation. Supervision and child-sized furniture and equipment in good condition are among top safety precautions for this age group. Proper diapering, toileting, feeding, and napping routines are essential to proper sanitation. Floors and toys must also be washed and sanitized often (Lowman \& Ruhmann, 1998). Bordin and colleagues (2000) examined the providers’ knowledge of children's development and health care routines compared to quality in a poor, rural area. Specifically, providers' knowledge of injury prevention and control, infectious disease reduction and management, sanitation and health practices were assessed. Providers who had been trained had significantly higher knowledge of these practices than the untrained, however the overall average was lower than knowledge of child development (Bordin et al., 
2000). It has been found that child care homes with more infants and toddlers enrolled have lower quality (Burchinal, Howes, \& Kontos, 2002). Loeb and colleagues (2004) found that children in poor communities are likely to have behavioral problems affecting their social development due to the quality of care. Norris (2001) also found that ongoing professional development correlated with better basic care. Rusby (2002) found that providers' worries of improving safety stem from affordability.

Childcare has shown to be of mediocre quality for pre-school age children and poor for infants and toddlers (Cryer \& Phillipsen, 1997; Cryer, 1999). Quality of the child care environment is hard to define because it is a subjective term. However, process quality in early childhood education consists of safe and healthful care, developmentally appropriate practice, positive relationships and interactions with adults and children, and promoting individual growth (Cryer, 1999). The Environmental Rating Scale (ERS) is a scale to assess quality of Early Childhood, Infant/Toddler, Family, and School-Aged child care environments. The FCCERS is used to assess quality in family child care settings and has importance in studying the first research question: Do FCCERS subscale scores differ between family child care homes and family child care facilities? The following section describes attributes of process quality in family child care as defined by the FCCERS.

Subscales of the family child care environmental rating scale. The FCCERS Revised Edition, containing indicators for 38 items across seven subscales, was used in this study to assess environmental quality (Harms, Cryer, \& Clifford, 2007). Following are descriptions of the importance of these subscales in family child care settings. The explanations of these subscales add clarity to the focus of this study. 
According to Cryer (1999), family child care homes with ratings of five or higher and where the provider was sensitive and responsive produced better outcomes for children. It is unfortunate that most of the child care quality in the United States is mediocre or poor. Mediocre care is defined by “care in which children’s basic needs are met, some warmth and support is provided by adults, and some learning experiences are provided” (Cryer, 1999, p. 50). Poor quality is found as such for lack of warmth and support, lack of materials to promote development, and safety and sanitation problems (Cryer, 1999). In a study by Cryer and Phillipsen (1997) the 10 lowest scoring items on the Infant/Toddler Environmental Rating Scale earned scores of three, which indicates minimal quality, and below. Not surprisingly personal grooming, meals/snacks, health practices, and diapering/toileting were among the lowest scores (Cryer \& Phillipsen, 1997).

Space and furnishings. The physical design of a child care should resemble homes and provide an open concept with secluded play places available. Outdoor spaces should resemble the natural settings of backyards with clear circulation as well. Design of child care has an impact on development and can help incorporate curriculum into the environment. Neighborhoods that are accessible, away from busy roads, noise, and danger, close to natural features and community resources are ideal for child care settings. Each child should have enough individual indoor and outdoor space. Natural lighting, vegetation, covered entry and other home-like aspects are recommended. The idea of modified open space creates ageappropriate activity pockets with the use of half walls or open archways. With the modified open plan comes greater interactions among children and adult-child interactions, such as sharing, participating, and cooperating. Each activity pocket should contain materials for a 
different developmentally appropriate interest area, for instance art, blocks, math, etc. This open concept helps to promote clean circulation and pathways as well (Moore, 1994).

Personal care routines. Personal care routines may seem to be easily explained when it comes to quality. Nutrition, meal, and snack times are one of the items on this subscale that is important and may be overlooked. According to the Nutrition and Physical Activity SelfAssessment for Child Care children should receive fruit served in its own juice and colorful vegetables with no additives regularly. They should not eat fried or pre-fried meats or potatoes or meats high in fats, but instead should be served lean meats. Drinking water, $100 \%$ fruit juice, and low-fat milk should be provided instead of sugary drinks. Children should be encouraged to try new foods. Food should not be used as a punishment or reward and neither should physical activity. Other food provided for snacks or celebrations should not be entirely high in sugar, salt, or fat. Family style sit down meals and snack time should occur. The provider should participate by sitting with children, eating the same things, and talking to them about healthy choices. It is also encouraged for the provider to attend nutrition trainings, provide education on nutrition to children and families, and have a written policy on nutrition (Trost, Messner, Fitzgerald, \& Roths, 2009).

Health and safety practice are two of the items on this subscale that need to be taken into great consideration. Because family child care come providers are only required to meet minimum standards they have little knowledge of health and safety practices and ways to improve them. In a study by Shallcross (1995), trainings were held to improve quality and professionalism. Health and safety and emergency situations were covered in trainings and workshops covered other topics of orientation, self-esteem, safety, creating healthy environment, professionalism, and rescue organization. 
Budgetary constraints keep family child care home providers from making necessary improvements that comply with regulations. Other reasons that advanced training did not occur was that family child care providers felt that meeting the minimum regulations was sufficient and that they did not need more training. They were not aware of health and safety in the family child care home. Public funding and resources were not available to provide more advanced training on health and safety in the home. Providers felt isolated and could not find time for trainings due to their long hours of self-employment. Also, states do not make family child care homes a top priority. The lack of education in the early childhood field also hindered providers from seeking additional training. Providers were more comfortable with their business the way it was rather than subjecting themselves to additional requirements and expenses. Health and safety training should be a top priority with state funding allocated for this purpose because children and their families are directly affected. Qualified training programs and qualified trainers are needed to increase knowledge in health and safety in family child care homes (Shallcross, 1995).

In studies on health and safety in child care it has been found that injuries are the leading cause of disability and death in children, and that most of them occur in the home even if an adult is nearby. It is no different in the family child care home where the most injuries occur in children birth to two-year-old. However, since family child care is preferred for this age group that is fitting. The playground is the most prominent spot for injury, particularly equipment and areas for gross motor activities. While children in child care setting are more apt to illnesses and infections, small facilities such as family child care settings where less than six children are present, have a reduced risk (Shallcross, 1995). 
Listening and talking. Of the 61 family child care home providers who participated in the study by Cress (1998) of literature in their child cares, only half read to children more than once, told them stories, or sang to them on a daily basis. Three out of five homes provided children with access to over 30 books and audiotapes. All of the children had access to at least on writing instrument. Children's own literacy development is mostly influences by the caregiver-s behaviors toward literacy and the literacy environment, including being read to, seeing others read, accessible materials, and discussion about literacy. Children need caregivers who model language and literacy. In the family child care home not only is it important for reading and writing materials to be available for children, but caregivers must assist and help scaffold with these tasks. Children should be encouraged to tell stories, recall events, read environmental print, participate in finger plays and rhymes as well (Cress, 1998).

Activities. As was previously addressed the physical space of the early childhood environment should contain activity pockets organized into interest areas. These interest areas can include but are not limited to blocks, dramatic play, manipulatives, art, library, discovery/science, sand and water, music and movement, housekeeping, etc. These interest areas offer children many new learning experiences and planned activities can be arranged around each interest area (Dodge, Colker, \& Heroman, 2002).

The use of electronics is one of the items on the Activities subscale and while some television used to entertain can cause aggression, anxiety, and obesity, quality education geared toward young children and their caregivers can help a child to development cognitively. Stations like the Public Broadcasting Service promote educational goals and school readiness in their programming and online resources. When used in small doses as a tool to promote development, electronics can do just that. The problem occurs when television is used to pacify children and 
pass the time for the provider (Annie E. Casey Foundation, 2006). In lieu of the television, another item on this subscale is active physical play, which children should be engaged in for at least an hour a day, and be able to go outside. The use of TV, video, and computer should be monitored and limited. Play equipment, both fixed and portable should be accessible and appropriate and safe. The provider should model physical activity with children and display physical activity in the environment. It is also encouraged for providers to attend workshops on physical activity, share information with children and families, and have a written policy as well (Trost et al., 2009).

Interaction. Children's cognition and social development are heightened when the child care provider is responsive. These responsive interactions with child care providers form a secure attachment and also lead to more positive interactions with peers. Shivers (2006) takes into account that while the home-like environment of in-home child care may score low on environmental quality they may have higher scores on interactions (Shivers, 2006).

Developmentally appropriate practice is used when caregivers use social interaction and scaffolding to guide children's individual development. When providers use developmental appropriate practice in the child care or educational environment it causes children to show less stressful behavior. In a study by Chang, Austin, and Piercy (2006) developmentally appropriate practice was examined to find that the most common forms, even among low quality family child care homes was through interactions between the provider and child. The highest used forms of developmentally appropriate practice were encouragement given by the provider, provider scaffolding for child, and motivating of children by the provider. When high developmentally appropriate practice was found in these homes the stress level if children was limited to passive behavior, just as nose picking or twirling hair. In the homes where there were low levels of 
developmentally appropriate practice the children's stress became active toward others. Hostile, aggressive, destructive behaviors were seen. Also in the study, it was found that in the homes with low developmentally appropriate practice where providers cared for their own children that more attention was paid to them and that the rules were not universal, as opposed to the homes with high developmentally appropriate practice where the provider's children were treated as equals. This confirms parental fears of not being satisfied with a provider who cares for their own children as well as others; however it also shows that quality is an influence (Chang et al., 2006).

Providers who perform high levels of developmentally appropriate practice handled passive stress by scaffolding or reinforcement to promote self-regulation. Adversely, low developmentally appropriate practice providers did not acknowledge passive stress behaviors. Active stress was handled when providers utilized developmentally appropriate practice by redirecting children and reminding them of appropriate behavior. Low developmentally appropriate practice providers continued to be unaware of aggressive or destructive accts and did not have appropriate methods to fix the problems (Chang et al., 2006). These are examples of the Interaction subscale of the FCCERS and show how quality of the family child care home or facility and the use of developmentally appropriate practice has an impact on supervision of play and learning, provider-child interactions, interactions among children, and discipline.

Positive teacher-child interactions, ones that are warm, responsive, and directed toward learning lead to literacy, language, and social development in the early childhood environment. Downer, Sabol, and Hamre (2010) proposed that when adults give emotional, organizational, and instructional support to children they gain social-emotional, academic-cognitive, and selfregulation skills. Emotional support helps children feel secure and able to explore. Caregivers 
can provide this support by creating an atmosphere that is welcoming, where the provider helps children communicate with one another, personalizes conversation to individual children, and allows children to make personal gains through independent work. Organizational support is purposefully created to control the environment. By having planned activities and routines children are taught to expect what is coming and can self-regulate. Self-regulation is the ability to be attentive and manage emotions and behavior. Children become more engaged and motivated in organized spaces. Instructional support is given through planned instruction, including facilitation of discussions and feedback. Children should be taught through scaffolding things that they can apply later on and should be given opportunities to problem solve. Instruction support also leads to academic gains (Downer et al., 2010).

Teacher-child interactions help children under three years old to make sense of the world around them and their experiences in it. Because family child care homes are a popular means of child care for this age group, investigating teacher-child interactions for toddlers are of importance. At this point in a child's life, when they are learning about language, a sense of self, and self-regulation, they need caregivers to scaffold. Thomason and La Paro (2009) defined teacher-child interactions as, “emotional support, behavior guidance, and language facilitation” (Thomason \& La Paro, 2009, p. 287.) The FCCERS subscale of Interaction includes such items as supervision of play and learning, provider-child interaction, discipline, and interactions among children. Also under the listening and talking subscale items include helping children understand and use language and using books, which could also account for teacher-child interactions according to Thomason’s definition.

The setting's emotional climate should promote autonomy in the children through the support of the caregiver. A secure attachment between child and caregiver will form when the 
provider is responsive and sensitive to a child's needs. It is important for providers to mode language by talking, using language that is advanced, and encouraging children's attempts to communicate. Behavior guidance, helping children to self-regulate and resolve conflicts, is also a key to development in this age group. Children can learn these behaviors through redirection, feedback, encouragement and praise, and by having limits set for them (Thomason \& La Paro, 2009).

Program structure. Schedules and routines not only help children feel secure and comfortable in their environment, but it helps reduce instances of behavior problems. Children need structure and regulation in their lives to develop emotionally, cognitively, and socially. Schedules of what a person will do and when provides consistency. Routines are the tasks performed regularly that often coincide with scheduling and help children become more independent. There are important factors to consider when planning schedules and routines for children: balancing activities, timing of activities, attention spans, alertness, adult-child ratios, other distractions in the environment, and that long free play brings play behavior. Choice activities, where children can choose from a number of options, are an additional way to enhance free play activities. It is important to introduce children to schedules and routines and also to tell them when something may change. Balanced and planned activities that give children choices promote engagement and self-regulation and introduce the child different social and educational situations. Such activities in the child care setting include small group and large group time, quiet time and active time, teacher directed and child directed activities, and indoor and outdoor play. All of these listed help children to know what to expect and how to act in different situations. The length of the activity also promotes socialization and cognition (Ostrosky, Jung, Hemmeter, \& Thomas, 2003). 
Parents and provider. Contrary to other literature on the topic, Bollin and Whitehead (1991) found that parents who are dissatisfied with their child's care arrangement utilize a family child care home and are mostly disappointed with the educational aspect that is lacking. Shared childrearing beliefs of mother and provider seem to be a satisfying quality of family child care. Parents often choose providers because of referrals, initial meetings, and their child's reaction to the provider and do not pay attention to the quality of care. Bollin and Whitehead (1991) found that parental satisfaction correlated positively with the setting quality, which was in turn correlated positively with the provider's family income. This is reasonable because the more income the provider earns the more the provider can maintain the upkeep and well-being of the child care setting to meet standards and children's developmental needs. Sharing of child rearing beliefs and attitudes created job satisfaction for provider and satisfaction of care arrangement for parents. Also, recent training increased providers’ professionalism towards parents as well as parents' satisfaction of the care arrangement. One of the negative correlates to the study was the presence of the provider's own children in the family child care home and parental satisfaction (Bollin \& Whitehead, 1991). This is unfortunate because many family child care home providers view caring for their own children while running a business as a positive aspect of their job.

Aspects of structural quality. Structural quality refers to factors such as provider education, experience, knowledge, group size, and ratios. For the purpose of the current study provider education and training will be examined to answer the following research question: Does provider's level of education differ by type of family child care?

Provider credentialing and education are factors of quality at all levels of child care. The National Institute of Child Health and Human Development found that children's development was positively correlated with the quality of care received (NICHD Early Child Care Research 
Network \& Duncan, 2003). Family child care providers have less formal education than their licensed counterparts who have obtained at least a high school diploma. They have less formal training, but typically more experience (Liu \& Anderson, 2010). The provider's level of education has been associated with quality of care and children's development (Burchinal et al., 2002; Clarke-Stewart, Vandell, Burchinal, O’Brien, \& McCartney, 2002; Lanigan, 2011; Raikes et al., 2005). Quality improves with higher education in the field of child development.

The effects of structural quality on process quality. As previously stated, process quality can be improved when structural quality is regulated (Bordin et al., 2000; Cryer, 1999). On the contrary, aspects of process quality can be hindered if structural quality is poor. Therefore, the final research question examines if the structural quality aspect of provider education affects FCCERS subscale scores, which assess process quality. “Children’s social, emotional, linguistic, and cognitive development are influenced by their daily experiences while in non-parental childcare, and a positive correlation exists between the quality of childcare and desirable child development outcomes” (Lanigan, 2011, p. 400).

Family child care has been described as mediocre or of low quality which has been associated with the caregiver’s level of education (Burchinal et al., 2002; Clarke-Stewart et al., 2002; Lanigan, 2011; Raikes et al., 2005). Providers with higher education and training, especially in a child development field provide higher quality care. These providers are more likely to provide better language development, learning activities, and have better knowledge of basic care (Cryer, 1999; Norris, 2001). Clarke-Stewart and colleagues (2002) also found that a child's cognitive and language development improved with higher levels of provider training and education. Higher quality is present when the provider engages children in opportunities for learning instead of the everyday routines of childcare. Low-quality ratings have been credited to 
family child care provider's activities involving daily routines such as napping, physical care, television watching with less time devoted to learning activities (Morrissey, 2007).

For the purpose of this study, providers' training and credentialing in areas of early childhood development accounted for education as well. Caregivers' level of training also correlates with the quality of care (Burchinal et al., 2002; Clarke-Stewart et al., 2002; Lanigan, 2011; Raikes et al., 2005). Providers who attended training throughout their career provide higher quality care (DeBord \& Sawyers, 1996; Norris, 2001). By seeking out advanced education and training these providers give quality care and show commitment to their line of work (Norris, 2001). Training promotes quality childcare by helping providers gain knowledge, awareness, and sensitivity. It has been found that family child care providers who attend trainings are younger and more committed to the field of child care (Norris, 2001). Providers who attended trainings were more aware of developmentally appropriate practice in the childcare profession (DeBord \& Sawyers, 1996). Professional development training is also correlated with the provider's level of education. More educated providers are more likely to participate in continued education through professional development (Norris, 2001; Walker, 2002).

Lanigan (2011) conducted a qualitative study of family child care providers, which offered professional development. Providers participated in annual focus groups, monthly mentor visits, and monthly professional development meetings by the same facilitator. This process, especially mentoring and home visits have shown to lead to improvements in quality (DeBord \& Sawyers, 1996; Lanigan, 2011; Rusby, 2002). They also preferred extensive training on one topic that was meaningful and specific to family child care. Some of the topics for training expressed by Rusby (2002) as meaningful to providers are managing problem behavior, developing meaningful activities and curriculum, and stress management. To reduce their 
hesitance of environmental ratings Lanigan (2011) examined a few items from the FCCERS each month with the provider. Improvement plans for these items were also created and implemented giving providers more knowledge of their child care environment, one aspect at a time (Lanigan, 2011).

Lanigan (2011) found that providers participating in professional development had positive feedback about work sampling and documentation of children's work and progress. Not only did these activities provide documentation, but also helped guide new activities to help foster development. Among process quality improvement were provider-child interactions, which were made better through environments filled with literacy and language and providers’ better understanding for enhancing children's development. Child guidance was also improved by preventing problem behavior from happening, by providing an environment that would foster cooperation in children, and by monitoring and guiding children away from problem behaviors before they occur. Providers felt more knowledgeable of the process and importance of documenting children's progress and abilities, even in daily observations. They were nearly a third more confident in meeting children's developmental needs through successfully running a quality family child care (Lanigan, 2011).

More educated providers participate in ongoing professional development throughout their career (Norris, 2001; Walker, 2002). Subsequently, more education leads to more compliance. In a study of registered family child care homes in Texas, where minimum standards are stringent, it was found that compliance and quality corresponded with training and education. Grubb (1993) examined the effect of caregiver competencies, in the form of education and training, on compliance with minimum standards to find that noncompliance was lower when providers had at least a high school diploma or GED, when they attended ongoing 
training, were oriented with standards, and/or belonged to a professional organization. To measure compliance the regulations used in Grubb’s study were organized similarly to the FCCERS, into the following sections: standards, children in care, health and safety, and child care in the registered family home. Then these sections were arranged into subheadings. According to the regulatory system, compliance was high when the environment was clean and safe and the provider was effective in caring for children. Noncompliance was attributed to the environment, child care practice, interactions with others, and the attitude of the provider (Grubb, 1993).

Disadvantages of family child care consist of "inconsistent quality, limited regulation and oversight, and varying levels of child care provider preparation and knowledge of early childhood” (Lanigan, 2011, p. 399). Providers of family child care homes need to have support and professional development that is specific to family child care, the setting, the environment, and the demographic to which they serve (Rusby, 2002). When a provider finds support they have higher commitment and a more positive attitude that promotes higher quality care and less turnover and social isolation. Lanigan (2011) found that family child care providers were more apt to complete professional development training when attending support groups with other family child care providers that addressed issues specific to their child care setting. Through professional development they gained confidence in their unique role in the field and found social support (Lanigan, 2011; Walker, 2002). “To achieve maximum quality, regulation should occur in tandem with a relationship-based support and professional development system that is strengths-based, nonjudgmental and distinct from licensing” (Lanigan, 2011, p. 407). 


\section{Justification of the Study}

According to the 2011 West Virginia Kids Count data book, released in early 2012, there are 1,835 registered family child care homes and 111 family child care facilities in the state. An overwhelming $60 \%$ of child care providers in the state of West Virginia have no training. Research on the quality of family child care homes and facilities is important in knowing how to maintain and improve quality and to ensure compliance with regulations and standards. This study was conducted to investigate the quality factors of family childcare in West Virginia by looking at the differences in the subscale scores, according to the FCCERS, of family child care homes and facilities. Provider training was also assessed by type of family child care. This study also investigated the highest and the lowest level of education and training at each site to examine the relation between provider education level and quality of the family child care setting. 


\section{Chapter II}

\section{Method}

There are differences in licensing requirements and procedures that family child care homes and facilities follow in the state of West Virginia. WVDHHR issues an initial certificate of registration to a family child care home upon application and self-certification of compliance (West Virginia Department of Health \& Human Resources, 2007). The department inspects every family child care facility before issuing a license (West Virginia Department of Health \& Human Resources, 2007). WVDHHR provided funding in early 2010 for the grant titled Quality Rating and Improvement for West Virginia Child Care. The purpose was to assess child care center, homes, and facilities using the Early Childhood Environmental Rating Scale, the Infant/Toddler Environmental Rating Scale, the Family Child Care Environmental Rating Scale, and the School Age Care Environmental Rating Scale to collect data. This study drew from existing data of family child care that was collected for the aforementioned grant.

\section{Procedures}

The grant recipient randomized a sample of all types of child care, assessed each randomly selected center, home, or facility, collected and entered data, collected demographic and contact information on the sites, established a baseline, and analyzed the quality of each type of child care setting, both separately and combined, based on teacher and director credentials. After obtaining consent from the Institutional Review Board, the project manager and five observer/trainers obtained two weeks of training on the rating scales. Each was trained to be reliable on two rating scales and upon return trained each other on remaining scales. Eight more observers were trained by the project manager and observer/trainers to be reliable. 
A full list of centers, homes, and facilities was provided by WVDHHR, and a statistician created a list of randomly selected centers to assess. There were 94 family child care facilities and 1,595 family child care homes provided by WVDHHR. All centers in the state were notified by WVDHHR that they might be selected for rating through the grant. Observers were to contact centers and homes before the visit, at which time numerous family child care homes refused to participate by letting their homes be assessed. Incentives were given for family child care homes, but they were still hesitant, causing the statistician to randomly select more homes from the list provided. This reselection process occurred five times throughout the data collection phase due to the reluctance of the providers. In previous research, Fiene and Melnick (1989) also found that many family child care homes on the list provided by their state's licensing department did not wish to participate and nearly three-fourths were no longer serving children. They also had to continue randomly selecting centers until the desired number was reached.

In the current study, a total of 29 family child care facilities and 55 family child care homes participated. The environmental rating scale score, tier level, director/provider experience, director/provider highest level of education, and director/provider training was also recorded. The project manager obtained the providers' highest level of education, training, and experience as well as the classroom teachers. This information was collected through self-reporting. Another important aspect to note is that many times, due to provider-child ratios in family child care homes, there is one provider in the setting. At the time of data collection family child care facilities had an average of 3.28 staff members employed while family child care homes had an average of 1.22. A majority of the teachers in this study had only a high school diploma (or equivalent) with one teacher not earning a high school degree and one currently working on a 
GED. Fifty-nine of the 84 directors had a high school diploma or less with only 14 directors having some type of degree in the field. In the teacher category, and in many cases the teacher and director is the same individual, there were 68 teachers with a high school diploma or below. Only six teachers had a degree in the field.

\section{Measures}

The FCCERS is a reliable and valid measure to assess quality in family child care homes. It represents an accurate portrayal of strengths and weaknesses in a program, indicating where improvements can be made (Harms \& Cryer, 2007). The revised version, which was used in the present study, has proven to be a reliable assessment instrument that is internally consistent and stable. "The assessment measures the more enduring aspects of quality that would not be expected to change radically from day to day” (Harms et al., 2007, p. 6).

The seven subscales of the FCCERS are Space and Furnishings, Personal Care Routines, Listening and Talking, Activities, Interaction, Program Structure, and Parents and Provider. There are 38 items across these subscales that can be scored between one and seven. Items scored one are inadequate, three are minimal, five are good, and seven are excellent. Each items score is added together to find a mean score that represents the quality of the child care home (Cryer, 1999). The key to the assessment is a well-trained observer to collect the data (Harms et al., 2007).

Indicators for indoor space used for child care are the first items to score on the subscale under Space and Furnishings. It is desirable for all items in column one to be marked as, "No" and the following items, "Yes." Indicators under the first column include not enough space for children, along with toys and furniture, space is not adequately ventilated, lighted, heated or cooled, or guarded for sound, space is in disrepair to the point where health and safety are 
compromised, and the space is unkempt. All of these items should be marked "No." The next column describes enough space for children, toys, and furniture, adequate lighting, ventilation, heating and cooling, and sound control. Space is in good repair and reasonably clean and maintained. Items in the next column include ample accessible space and furnishings, some natural light, and is handicap accessible to individuals already using the home. The last column depicts exemplary space and furnishings. Items scoring a seven would have natural light, ventilation control, easy to clean floors, walls, and surfaces, and spaces that are accessible to children and adults with disabilities. All indicators for the given column, one, three, five, or seven must be met to achieve that score. If only half of the indicators are met the item is scored as the next lowest number. All indicators in the first column must be scored "Yes" to receive the lowest score of one. This is also the only column in which "No" is the desired answer. A score of two is achieved when all items under number one are scored "No" and half or more of the indicators under three are scored "Yes". A score of three is achieved when all items in column one are scored "No" and all items in column three are scored "Yes". A score of four is met when half or more of the indicators for five are met and all are met for column three. When all indicators for one are "No", and all indicators for three and five are "Yes", a score of five is given. A score of six is given when all item one indicators are "No", item three and five indicators are all "Yes", and at least half of the indicators under seven are marked as "Yes". A perfect score of seven is met when all items under column one are "No" and the rest of the indicators are "Yes” (Harms et al., 2007). The remainder of items to score for Space and Furnishings include furniture for routine care, play, and learning, provision for relaxation and comfort, arrangement of indoor space for child care, display for children, and space for privacy. 
The next subscale is Personal Care Routines with items for greeting/departing, nap/rest, meals/snacks, diapering/toileting, health practices, and safety practices. The Listening and Talking subscale includes items for helping children understand language, helping children use language, and using books. The Activities subscale includes fine motor, art, music and movement, blocks, dramatic play, math/number, nature/science, sand and water play, promoting acceptance of diversity, use of TV, video, and/or media, and active physical play. Items under the Interaction subscale include supervision of play and learning, provider-child interaction, discipline, and interaction among children. Program Structure, the next of the subscales, includes items for schedule, free play, group time, and provisions for children with disabilities. The last subscale, Parents and Provider, includes the following items: provisions for parents, balancing personal and caregiving responsibilities, opportunities for professional growth, and provisions for professional needs (Harms et al., 2007). Anecdotal notes from the observer/trainers and observers were also collected as qualitative data. The anecdotal notes included comments from the individual score sheets as well as ending reflections on their experiences with the data collection process.

\section{Data Analysis}

Both FCCERS scores and anecdotal notes were hand-recorded by observer/trainers and observers who were reliable in the rating scale in compliance with the WVDHHR grant, Quality Rating and Improvement for West Virginia Child Care. Once data collection was complete the data entry began. SKIPPER was used to analyze the scores collected. Data was entered in a batch method where paper forms of the observers' ERS score sheets were sorted into types of child care. Once sorted a data entry operator entered the information into the database, which was then imported to Microsoft Excel and analyzed using SPSS. Data entered contained scores, 
provider information, and anecdotal notes. Anecdotal notes were transferred from handwritten score sheets and typed into Microsoft Excel. The scores and anecdotal notes were used to assess the first research question: Do FCCERS subscale scores differ between family child care homes and family child care facilities?

To consider the second research aim, which was to investigate a difference of provider's level of education between family child care homes and family child care facilities, the highest and lowest level of education at each site was coded. Level zero was assigned to any caregiver who had not obtained a high school diploma. Caregivers at level one were currently enrolled in high school or GED equivalent classes. There was one provider in this category with no higher than an $11^{\text {th }}$ grade education and was working on completion of a GED at the time of data collection. Level two was defined to directors and teachers with a high school diploma or GED, which made up the majority of the participants. Level three was assigned to one provider whose highest level of training was the West Virginia Infant/Toddler Training after high school. Directors and teachers at level four had obtained a Child Development Associate credential and level five an Apprenticeship for Child Development Specialist certification. Level six was defined as providers who have a high school diploma and some college education. This data was self-recorded by directors and teachers and was also assigned to a Certified Nursing Assistant because of the vocational training obtained. Associate's Degree out of the field were found in level seven participants with level eight being Associate’s Degree in the field. To be considered in the field the degree must have been in Child Development or Early Childhood Education. Level nine is defined as a Bachelor's Degree out of the field and level 10 Bachelor's Degree in the field. Elementary education was coded as a Bachelor's Degree out of the field of early childhood education. Providers reaching level 11 had obtained a Master's Degree out of the field 
and level 12 consisted of a Master's Degree in the field. A Master's Degree in reading was coded as out of the field. Lastly, level 13 had achieved a Doctorate out of the field and level 14 a Doctorate in the field. A level 14 Doctorate in the field was applied to one provider in the family child care home setting.

Once coded, the highest and lowest levels of provider education were added to existing family child care data in SPSS. To further examine the second research question, highest and lowest provider education levels were examined by type of care, facility or home. Independent samples tests were run to examine equality of means and variance. To examine the third and final research aim Spearman's rho correlation was used as an ordinal scale to test significance between the levels of education on subscale scores within both the family child care home and facility settings. Outputs included correlations between subscale scores and education levels of overall family child care, as well as family child care facilities and family child homes individually. 


\section{Chapter III}

\section{Results}

The first focus of the study was to determine to what extent FCCERS scores vary between family child care facilities and family child care homes. Table 1 presents subscale scores and mean difference levels for each type of care.

Table 1

Quality Subscale Scores of Family Child Care Facilities and Homes in West Virginia as Measured by the FCCERS (with Standard Deviations in Parentheses)

\begin{tabular}{llll}
\hline \multicolumn{1}{c}{ Subscale } & $\begin{array}{l}\text { Facilities } \\
(n=29)\end{array}$ & $\begin{array}{l}\text { Homes } \\
(n=55)\end{array}$ & $\begin{array}{l}t \\
(d f=82)\end{array}$ \\
\hline QRS Mean & $3.92(0.97)$ & $3.32(1.00)$ & $2.62^{*}$ \\
Space/Furnishings & $4.04(1.10)$ & $3.21(1.11)$ & $3.25^{* *}$ \\
Personal Care Routines & $2.57(0.93)$ & $2.49(1.07)$ & .34 \\
Activities & $3.25(1.05)$ & $2.63(0.85)$ & $2.96^{* *}$ \\
Interaction & $5.38(1.39)$ & $5.14(1.59)$ & .69 \\
Listening/Talking & $4.52(1.55)$ & $4.31(1.58)$ & .57 \\
Program Structure & $4.72(1.84)$ & $3.87(1.89)$ & $1.99^{*}$ \\
Parents/Provider & $4.96(1.25)$ & $3.62(1.48)$ & $4.15^{* *}$ \\
\hline
\end{tabular}

Note. ** Mean difference is significant at the 0.01 level.

* Mean difference is significant at the 0.05 level.

Family child care homes in West Virginia are of low quality as measured by the FCCERS. Family child care homes were of lower quality across every subscale and overall quality score according to the FCCERS. Family child care facilities had a mean quality score of 3.92 compared with family child care homes, which received a mean FCCERS score of 3.32. Family child care facilities had a mean score of 4.04 on the space and furnishings subscale. Personal care routines, which were low for both types of care, had a mean score of 2.57 at the level of family child care facilities. Family child care facilities scored 3.25 on the activities subscale. 
The interaction subscale had a mean score of 5.38 in family child care facilities, followed by the listening and talking subscale with a mean score of 4.52. Program structure in family child care facilities had a mean score of 4.72. The parents and provider subscale received a mean score of 4.96 in family child care facilities.

Family child care homes had a space and furnishings mean score of 3.21. Personal care routines in family child care homes had the lowest mean score of 2.49 . In family child care homes the mean score on the activities subscale was 2.63. The mean score for the interaction subscale was the highest of the subscales for family child care homes at 5.14. The mean score for the listening and talking subscale was 4.31. In family child care homes the mean score on the program structure subscale was 3.87. The parents and provider subscale received a mean score of 3.62. Subscales on which mean differences in scores were found to be significant were space and furnishings, activities, program structure, and parents and provider, along with the QRS mean.

The average score for the personal care routines subscale was below minimal quality for both types of care, as was the average score for the activities subscale in family child care homes. The activities subscale score for family child care facilities was barely above the minimal threshold, and was still the second lowest subscale score for that type of care. The interaction subscale scores were the highest between both types of care, however, higher among family child care facilities. Family child care facilities had an average score of good quality on the interaction subscale.

To add to the subscale scores, anecdotal notes were recorded at each family child care site (see Appendix). The subscale for personal care routines includes the following items: greeting/departing, nap/rest, meals/snacks, diapering/toileting, health practices, and safety 
practices. Anecdotal notes were taken at each site along with the FCCERS evaluation. In one center children could come and go as they pleased, and walked home. In several centers there was no designated area for naps and children slept together on the couch or wherever they fell asleep. There were several complaints about meal and snack time. Many of them being that there was a lack of hand washing and sanitization. In an extreme case a cookie fell on the floor and was placed back in a child's bowl. The same issues were witnessed during toileting and diapering where proper hand washing and sanitization did not take place. In some family child care settings, children were changed on beds or on the floor where other children play. Some of the more severe lack of health practices were seen when providers were either smoking cigarettes around children or cigarettes were in the reach of children. There were several safety hazards including the following items in children's reach: nails, screws, uncovered outlets, cat litter, medicine, cigarettes, uncovered pool, glass objects, fuel can, rusty items, heater, grill, and a lawnmower. These are just a few of the discouraging anecdotal notes recorded for the lowest subscale in both types of care.

The next lowest scores in both family child care homes and facilities were found in the activities subscale. The activities subscale includes fine motor, art, music and movement, blocks, dramatic play, math/number, nature/science, sand and water play, promoting acceptance of diversity, use of TV, video, and/or media, and active physical play. Fine motor, art, music and movement, blocks, dramatic play, math/number, nature/science, and sand and water play are all important interest areas for children's development. Most of the anecdotal notes on these items described a lack of materials. Materials were either not accessible to children, were limited, were not existent at all, and provider did not guide children in meaningful development tasks. Other anecdotal notes described how diversity was not promoted. Baby dolls were all one race. 
Materials highlighting abilities and gender were not present. In some family child care settings, the television was on the entire day with no monitoring. In these cases violent or inappropriate content and video games were viewed. Hazardous areas and materials were mainly described for the item of active physical play.

The interaction subscale, which was highest between both types of care, includes supervision of play and learning, provider-child interaction, discipline, and interaction among children. The following positive interactions were anecdotally collected at family child care facilities and homes. One provider made and explained a game to children. Another praised children's accomplishments by telling them that they were sharing nicely. At another site there were two providers present, therefore one provider was engaged with children inside while the other provided supervision outside. Many providers disciplined through redirection and by placing children in a time out followed by an explanation. Many providers also assisted children in learning tasks and encouraged children to communicate with one another.

The second research question aimed to find out if provider's level of education differs by type of care. Table 2 shows the mean levels of education between family child care homes and facilities.

Table 2

Highest and Lowest Provider Education Level Means of Family Child Care Facilities and Homes in West Virginia (with Standard Deviations in Parentheses)

\begin{tabular}{lllc}
\hline \multirow{2}{*}{ Education Level } & \multicolumn{3}{l}{ Type of Care } \\
\cline { 2 - 4 } & Facilities & Homes & $t(d f)$ \\
\hline Highest & $6.66(3.06)$ & $4.02(3.21)$ & $3.64(82)$ \\
Lowest & $3.86(2.81)$ & $3.64(3.18)$ & $.32(82)$ \\
\hline
\end{tabular}

Note. $*$ Mean difference is significant at the 0.01 level. 
Providers of family child care facilities had higher averages of highest education level (6.66) and lowest education level (3.86) than family child care homes. There was less difference between education levels and family child care homes; highest level of education among family child providers had a mean of 4.02 and their lowest level of education had a mean of 3.64. A possible explanation for the difference in variance between types of care could be that the provider and teacher was the same person, meaning that the highest level of education at the site was also the lowest. Family child care facilities had an average of 3.28 staff members present while family child care homes had an average of 1.22 staff members. Family child care facilities had significantly higher levels of education, but there was no significant difference in levels of education and type of care. These findings are presented in the following Table and Figures.

Table 3 expresses the totals for highest and lowest education levels (from zero to 14) found at each site. Thirty-five family child care home providers' highest level of education was a high school diploma or GED, compared with eight providers of family child care facilities, whose highest level of education was a Bachelor's degree in the field. The most frequently found lowest level of provider education for both types of care was a high school diploma or GED, with 17 family child care facility providers and 40 family child care home providers at that level. This table also shows the range of education levels among types of care. Family child care homes' highest and lowest education levels ranged from level zero to 14, with one provider having no diploma and one obtaining a Doctoral level degree in the field. Providers of family child care facilities had lowest education levels from one to 10 (currently enrolled in GED courses and Bachelor's in the field) and highest from two to 10 (high school diploma or GED and Bachelor's in the field. 
Table 3

Highest and Lowest Provider Education Levels of Family Child Care Facilities and Homes in West Virginia

\begin{tabular}{|c|c|c|}
\hline Education Level & $\begin{array}{l}\text { Facilities } \\
(n=29)\end{array}$ & $\begin{array}{l}\text { Homes } \\
(n=55)\end{array}$ \\
\hline \multicolumn{3}{|c|}{ Highest Education Level at Site } \\
\hline 0 & 0 & 1 \\
\hline 1 & 0 & 0 \\
\hline 2 & 6 & 35 \\
\hline 3 & 1 & 0 \\
\hline 4 & 0 & 0 \\
\hline 5 & 2 & 2 \\
\hline 6 & 5 & 6 \\
\hline 7 & 1 & 2 \\
\hline 8 & 3 & 0 \\
\hline 9 & 3 & 4 \\
\hline 10 & 8 & 3 \\
\hline 11 & 0 & 1 \\
\hline 12 & 0 & 0 \\
\hline 13 & 0 & 0 \\
\hline 14 & 0 & 1 \\
\hline \multicolumn{3}{|c|}{ Lowest Education Level at Site } \\
\hline 0 & 0 & 1 \\
\hline 1 & 1 & 0 \\
\hline 2 & 17 & 40 \\
\hline 3 & 0 & 0 \\
\hline 4 & 1 & 0 \\
\hline 5 & 3 & 3 \\
\hline 6 & 1 & 0 \\
\hline 7 & 1 & 2 \\
\hline 8 & 2 & 0 \\
\hline 9 & 1 & 4 \\
\hline 10 & 2 & 3 \\
\hline 11 & 0 & 1 \\
\hline 12 & 0 & 0 \\
\hline 13 & 0 & 0 \\
\hline 14 & 0 & 1 \\
\hline
\end{tabular}


Figures 1 and 2 depict the highest levels of education in family child care facilities and homes. Figures 3 and 4 express the lowest levels of education between types of care.

Figure 1

Highest On-Site Provider Education Level of Family Child Care Facilities in West Virginia

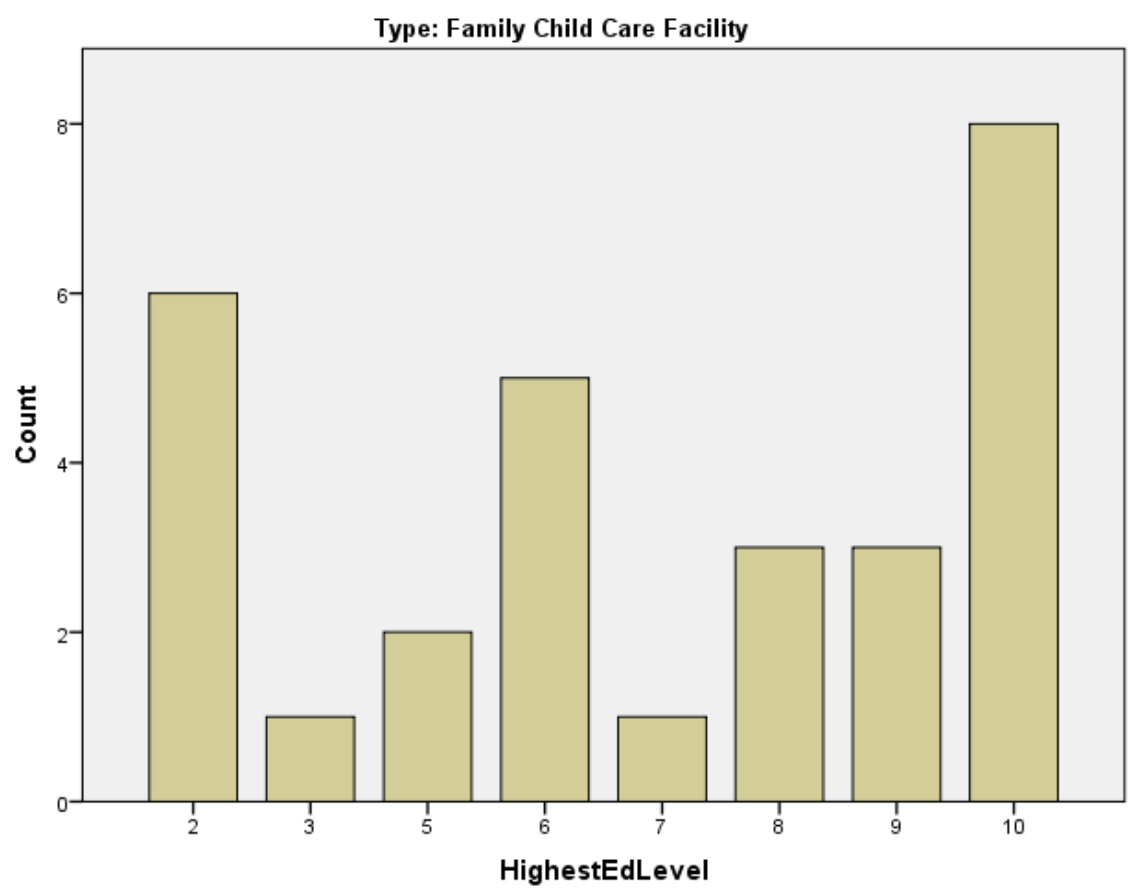

Figure 2

Highest On-Site Provider Education Level of Family Child Care Homes in West Virginia

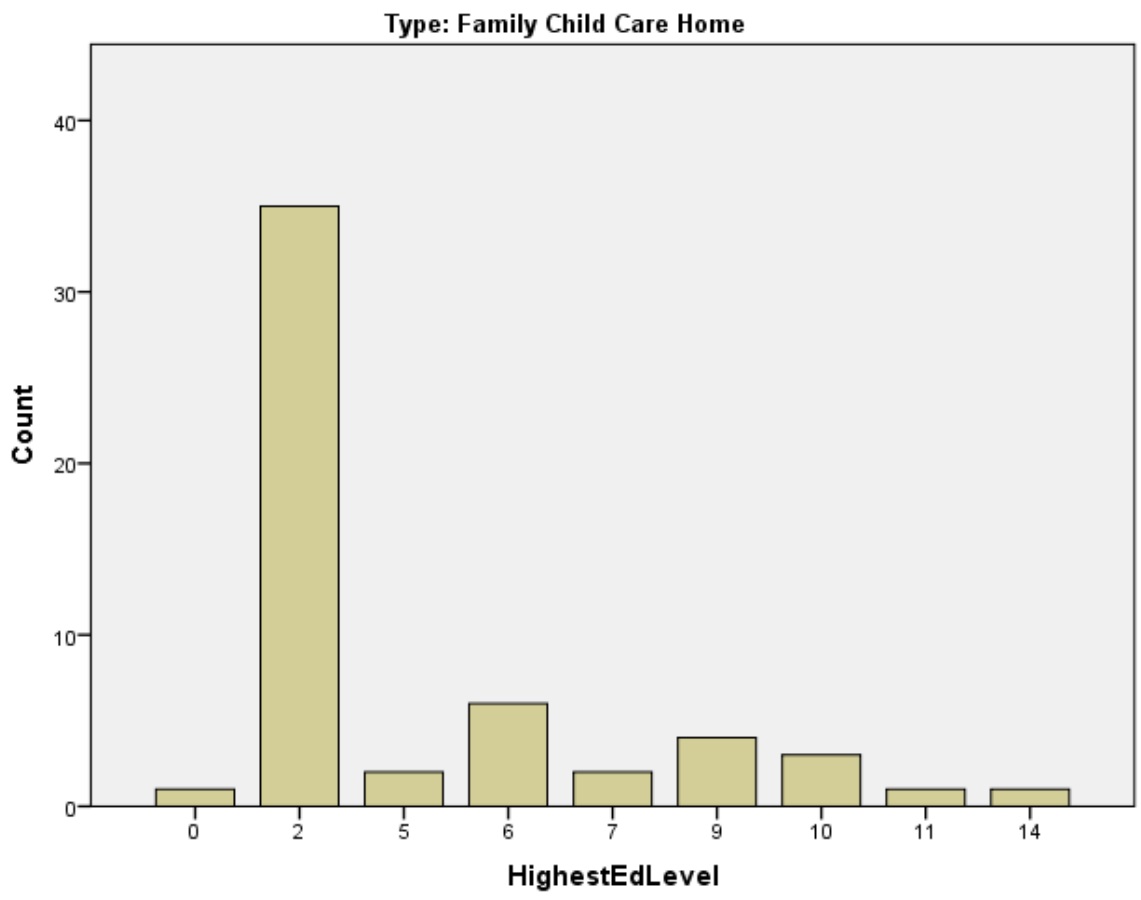


Figure 3

Lowest On-Site Provider Education Level of Family Child Care Facilities in West Virginia

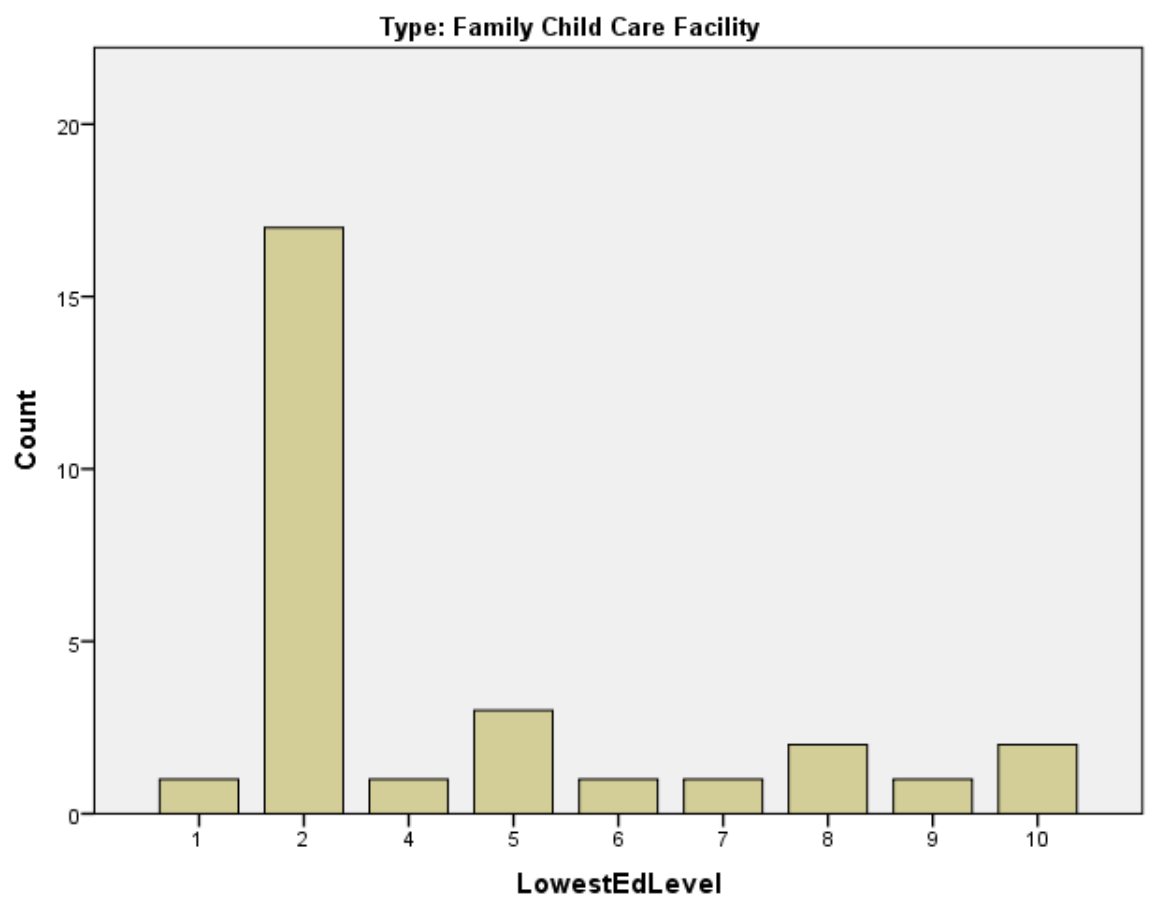

Figure 4

Lowest On-Site Provider Education Level of Family Child Care Homes in West Virginia

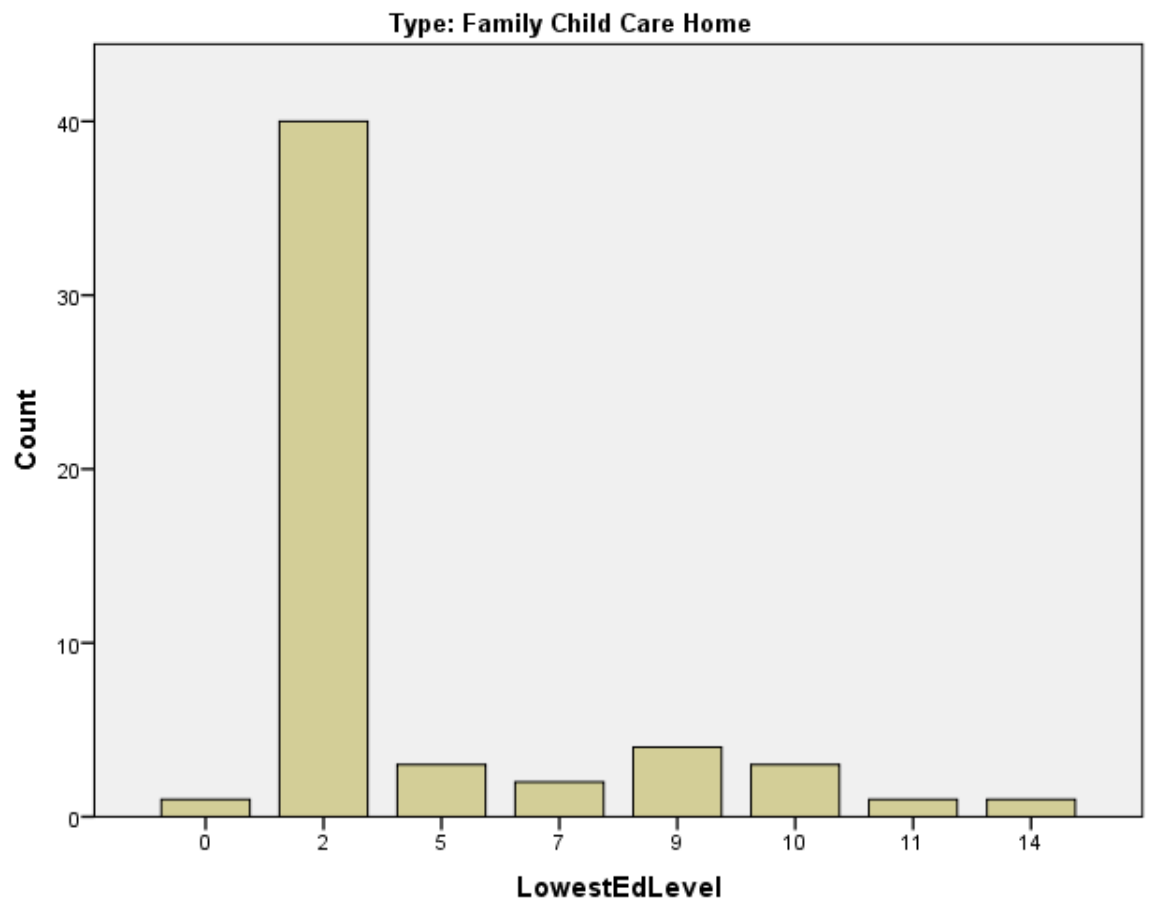


The figures also display the difference in variance between education level and type of care. There was little variance found between the highest and lowest levels of education in family child care homes, as displayed in Figures 2 and 4. There was also little variance shown between lowest level of education of family child care facilities and both education levels of family child care homes. Figures 2 and 3 show many similarities when comparing the highest education levels of family child care homes with the lowest education levels of family child care facilities. Once again in family child care homes the provider and teacher are often the same person, confirmed by the number of staff present which was 1.22 . Table 4 shows the minimums and maximums of highest and lowest levels of provider education across types of care. The range of highest levels of education for family child care facilities is from two to 10, while the lowest range from levels one to 10 . Highest and lowest levels of provider education for family child care homes ranged from zero to 14 .

Table 4

Minimum and Maximum Levels of Education found in Family Child Care Facilities and Homes in West Virginia

\begin{tabular}{lll}
\hline Education Level & $\begin{array}{l}\text { Facilities } \\
(\mathrm{n}=29)\end{array}$ & $\begin{array}{l}\text { Homes } \\
(\mathrm{n}=55)\end{array}$ \\
\hline Highest Minimum & 2 & 0 \\
Highest Maximum & 10 & 14 \\
Lowest Minimum & 1 & 0 \\
Lowest Maximum & 10 & 14 \\
\hline
\end{tabular}

The final research question explored how subscale scores between type of care related to provider's level of education. These findings are presented in Table 5. 
Table 5

Correlations between Overall FCCERS Subscale Scores and Highest and Lowest Levels of Provider Education in West Virginia

\begin{tabular}{lll}
\hline & \multicolumn{2}{c}{ Education Level } \\
\cline { 2 - 3 } \multicolumn{1}{c}{ Subscale } & Highest & Lowest \\
\hline QRS Mean & & $0.28^{*}$ \\
Space/Furnishings & $0.35^{* *}$ & 0.17 \\
Personal Care Routines & $0.35^{* *}$ & $0.25^{*}$ \\
Activities & 0.17 & $0.26^{*}$ \\
Interaction & $0.35^{* *}$ & $0.22^{*}$ \\
Listening/Talking & $0.23^{*}$ & $0.27^{*}$ \\
Program Structure & $0.27^{*}$ & 0.19 \\
Parents/Provider & $0.35^{* *}$ & 0.21 \\
& $0.30^{* *}$ & \\
\hline
\end{tabular}

Note. ** Correlation is significant at the 0.01 level (2-tailed).

* Correlation is significant at the 0.05 level (2-tailed).

Overall, FCCERS means were significantly correlated to highest and lowest levels of education.

The correlation coefficient between FCCERS mean and highest level of education (0.35) was significant. The correlation coefficient between FCCERS mean and lowest level of education (0.28) was significant. The space and furnishing subscale correlated with highest level of education with a correlation coefficient of 0.35 . Space and furnishings did not have a correlation with lowest level of education. Personal care routines were not correlated with highest level of education. Personal care routines showed a correlation coefficient of 0.25 with the lowest level of education and were significant. The activities subscale was significantly correlated with highest (0.35) and lowest (0.26) levels of education, also showing significance with highest and lowest levels of education. Both interaction and listening and talking subscales, which were among the highest subscale scores for both family child care homes and facilities, showed significance with little variability at the highest and lowest levels of education. The correlation 
coefficient between interaction and highest level of education was 0.23 and lowest level of education was 0.22. Correlation coefficients between listening and talking and highest level of education was 0.27 and 0.27 between lowest levels of education. Program structure subscale was highly correlated (0.35) to highest level of education, but did not correlate with lowest level of education. The parents and provider subscale was also significantly correlated with highest level of education with a correlation coefficient of 0.30 , but not with lowest level of education. The following subscales are correlated to highest education level only: space/furnishings, program structure, and parents/provider. As education levels increase, subscale scores will do the same. Personal care routines, however, was only correlated with the lowest education level. Personal care routines were also the lowest subscale for both types of care. There is more potential for less educated providers to increase their education, training, and score on this subscale than providers who already have high levels of education and training.

Correlations at the subscale level specific to the family child care facility are presented in Table 6. There was no significance found between scores on the space and furnishings subscale and highest or lowest levels of education. There was a significant correlation (0.39) between personal care routines (lowest subscale score) and lowest level of education, indicating that less educated providers have more potential to increase scores when education level is also increased. No significance between the personal care routines subscale and highest level of education was found. There was no significance found between scores on the remaining subscales and highest or lowest levels of education of family child care facility providers. 
Table 6

Correlations between FCCERS Subscale Scores of Family Child Care Facilities and Highest and Lowest Levels of Provider Education in West Virginia

Education Level

\begin{tabular}{lll}
\cline { 2 - 3 } \multicolumn{1}{c}{ Subscale } & Highest & Lowest \\
\hline QRS Mean & & 0.15 \\
Space/Furnishings & 0.06 & 0.08 \\
Personal Care Routines & 0.23 & $0.39 *$ \\
Activities & 0.11 & 0.10 \\
Interaction & -0.00 & 0.14 \\
Listening/Talking & 0.07 & 0.15 \\
Program Structure & 0.00 & -0.04 \\
Parents/Provider & 0.06 & 0.30 \\
\hline
\end{tabular}

Note. * Correlation is significant at the 0.05 level (2-tailed).

Displayed in Table 7 are correlations specific to family child care homes and subscales of the FCCERS.

Table 7

Correlations between FCCERS Subscale Scores of Family Child Care Homes and Highest and Lowest Levels of Provider Education in West Virginia

\section{Education Level}

\begin{tabular}{lll}
\cline { 2 - 3 } \multicolumn{1}{c}{ Subscale } & Highest & Lowest \\
\hline QRS Mean & & $0.31^{*}$ \\
Space/Furnishings & 0.24 & 0.21 \\
Personal Care Routines & 0.16 & 0.19 \\
Activities & $0.33^{*}$ & $0.32^{*}$ \\
Interaction & $0.27^{*}$ & 0.25 \\
Listening/Talking & $0.36^{* *}$ & $0.34^{*}$ \\
Program Structure & $0.36^{* *}$ & $0.29 *$ \\
Parents/Provider & 0.23 & 0.12 \\
\hline
\end{tabular}

Note. ${ }^{* *}$ Correlation is significant at the 0.01 level (2-tailed).

* Correlation is significant at the 0.05 level (2-tailed). 
The mean FCCERS scores across family child care homes were significantly correlated to highest (0.34) and lowest (0.31) level of education. Coefficients between highest and lowest education levels of education and space and furnishings were not significant. There was no significance found between scores on the personal care routines subscale and highest or lowest levels of education. The activities subscale scores were also significantly correlated to highest (0.33) and lowest (0.32) level of education. The interaction subscale was significantly correlated only to highest level of education with a correlation coefficient of 0.27 , but was not correlated to lowest level of education. The listening talking subscale was correlated to the highest level of education (0.36) and to the lowest level of education (0.34). Also, the program structure subscale was correlated with highest level of education and a correlation coefficient of 0.36. Program structure correlated with lowest level of education with a correlation coefficient of 0.29 . There was no significance found between scores on the parents and provider subscale and highest or lowest levels of education of family child care homes. The interaction subscale was the highest score among family child care homes and was also correlated to highest levels of education, meaning that scores for this subscale can increase with education. 


\section{Discussion}

The current study followed three reasons questions to extrapolate the following findings. The first research question is as follows: Do FCCERS subscale scores differ between family child care homes and family child care facilities? Family child care facilities scored higher on every subscale of the FCCERS. Average scores for personal care routines and activities were below the minimum of three in family child care homes. Personal care routines were also lower than three in family child care facilities and the activities subscale score was among the lowest. Basic care as well as learning activities can be improved when the provider's level of education increases (Cryer, 1999; Norris, 2001). In order for providers to score higher on the activities subscale children should be engaged in opportunities for learning instead of the everyday routines of childcare (Morrissey, 2007).

Interaction was found to be the highest subscale score for both types of care. Interaction was slightly higher in family child care facilities, and was the only subscale between both types of care that received a score indicating good quality. This finding alone tells a lot about the regulating system in West Virginia if only one subscale between both types of family child care was found to be of good quality. The rest of the subscale scores were at or below minimal levels of quality. The listening and talking, program structure, and parents and provider subscales were also among the highest scores for both family child care homes and facilities. These findings were consistent with the Quality Rating and Improvement for West Virginia Child Care grant with child care centers (2010).

The second research question investigated the difference in provider's level of education

between family child care homes and facilities. Not only did facilities score higher on all subscales of the FCCERS, but higher means of higher levels of education were found in family 
child care facilities as well. Provider education levels were especially low among family child care home providers, with one provider having no higher than an $11^{\text {th }}$ education. A majority of the providers in this study had only a high school diploma or GED equivalent with one provider not earning a high school degree. Fifty-nine of the 84 directors had a high school diploma or less with only 14 directors having some type of degree in the field. In the teacher category, and in many cases the teacher and director is the same individual, there were 68 teachers with a high school diploma or below. Only six teachers had a degree in the field. These statistics are especially troubling in light of research, which states that quality is related to level of education and training (Burchinal, Howes \& Kontos, 2002). Past research has found that the quality of care is not associated with age or years of experience but is positively correlated with the training and education the provider has received. Variations in quality are closely related to the characteristics of individual caregivers, including their level of education and training (Morrissey, 2007).

In the current study, higher means of higher levels of education were found in family child care facilities, even though the highest level of education at the Doctorate level was found in a family child care home. There was not a lot of variability between means of highest and lowest education level in the family child care homes. The slight variance could be due to the fact that the director and teacher in family child care homes is often the same person because of lower enrollment and the teacher-child ratios being one to six. Also a possible explanation could be the larger number of family child care homes (55) compared with only 29 facilities. The homes had less leverage for movement when determining means.

The final research question follows: How do subscale scores relate to provider's level of education? The overall FCCERS scores of both family childcare homes and facilities were 
related to the provider's level of education, both low and high. Higher levels of education were needed to achieve higher scores on the space and furnishings, program structure, and parents and provider subscales. Lowest levels of education were correlated with subscale scores for personal care routines, meaning that there is major room for improvement in family child care settings where the education level of the provider is low, but not a lot of room for improvement when higher education levels are present. This means that higher levels of education were needed to achieve a higher score on this subscale. Education level and subscale scores can only increase to a certain point, and then they will plateau. For example, once a provider is trained in and practices proper health and safety techniques, they should not regress in their subscale score. Without higher levels of training providers may not know that indoor and outdoor space should provide natural light, ventilation control, easy to clean floors, walls, and surfaces, and space that is accessible to children and adults with disabilities.

Personal care routines, which include health and safety practices, were not correlated with highest level of provider education. The correlation with the lowest level of education instead of the highest means that scores can increase as education levels increase, but if the level of education is already high the score will remain the same. Higher levels of education are needed to obtain adequate scores in the subscales of program structure, which includes a daily schedule that meets children's developmental needs. Higher education levels are also needed to obtain higher scores for the parents and provider subscale, which includes professionalism and balancing work with other responsibilities.

The same finding was presented in the data collected on family child care facilities and provider education alone. Both highest and lowest levels of education were significant on the activities, interaction, and listening and talking subscales. There was also little variability of 
correlation coefficients on the interaction and listening and talking subscales overall. The finding that scores between personal care routines and lowest level of education only was comparable to the overall correlations indicates that scores can increase as education levels increase, but plateaus at a certain education level.

More significant correlations were shown among family child care homes, likely because they need more improvement on scores and had lower levels of provider education. The interaction subscale was significantly correlated only to highest level of education. To interpret this finding, providers need to be educated to provide children with meaningful interactions. Interactions included in this subscale are not limited to provider-child interactions, but also include supervision and interactions among children. Lanigan (2011) stated that higher education leads to ongoing professional development and training, which in turn leads to more meaningful interactions and monitoring in the family child care home. For this population, made up of rural family child care home providers, experience rather than education may have provided them with higher subscale scores for interaction. The slight variability and significance of both highest and lowest levels of education might mean that providers don't need formal training and higher education to be able to communicate effectively and appropriately with children. Whereas, personal care routines and activities would require more education to achieve higher subscale scores. 


\section{Limitations \& Future Research}

Limitations occurred because the list of child care facilities and homes provided by WVDHHR was not current. There were centers with wrong addresses or phone numbers, telephones that went unanswered, sites that were no longer in business or serving children, and sites that were out of state. Noncompliance was the major limitation for family child care homes. All 94 family child care facilities on the list provided by WVDHHR were selected for observation and 29 (30\%) of them participated. Of the 1,595 family child care homes listed 570 (36\%) were randomly selected, but only 55 (10\%) participated. Due to the lack of participation, the findings are not generalizable. According to the 2011 West Virginia Kids Count data book, released in early 2012, there are 1,835 registered family child care homes and 111 family child care facilities in the state. These more accurate counts would have been helpful at the time of the data collection.

Family child care homes in West Virginia are of low quality as measured by the FCCERS. In addition to the Environmental Rating Scale data from the observers/trainers and the observers, the anecdotal notes must be given some thought. If the 83 homes/facilities of the many sites contacted were of poor quality as indicated in the FCCERS scores and by the anecdotal observations of the observers, then one could speculate about the ones that would not let the observers in to do an observation. These providers were given notice of when the observations could be done. If the observers and observer/trainers witnessed such incidences of noncompliance, then how do the licensing agents miss the obvious infractions?

A recommendation would be to look at the "inspection" system, not so much at the guidelines and requirements as they are updated periodically, but at the personnel doing the inspections. This baseline has shown that better prepared directors with education in the field 
have better scores; it would seem that personnel who have the same type of qualifications would be more capable of doing authentic inspections and also provide guidance for improvement. In a recent study (Lanigan, 2011) on family child care providers' opinions on appropriate professional development, it was found that child care providers feel isolated and need supportive social relationships with other family child care providers and the early learning professionals who are providing the professional development. A system that used a mentoring approach with one trainer was the most effective. They also preferred a series of trainings on a single topic rather than a one-time training on varied topics. In this study, it was more beneficial for family child care homes to focus on a few items from the FCCERS each month. Collaborative development of an improvement plan was an effective way to build communication.

Areas of future research would be to replicate the study among other rural populations across the United States in an effort to improve regulations. The findings of the current study were not generalizable. Therefore, replicating the study could add to its strength. Looking at the relationship between family child care providers' years of experience and subscale scores would also add to the research. As previously stated, the high subscale scores for interaction among family child care providers could be due to experience instead of levels of education. Correlations between subscale scores and providers' years of experience would provide possible answers to that phenomenon. A qualitative study of family child care providers and their ability to separate their personal life and career could also add to the body of research on the topic. Turnover rates among family child care providers have been found to be high because of their inability to separate their career from their personal life. Providers may become more lax in the 
way they run their small businesses because of the comfort they feel in their own home, which could be related to lower scores on FCCERS subscales.

Disadvantages of family child care consist of “inconsistent quality, limited regulation and oversight, and varying levels of child care provider preparation and knowledge of early childhood” (Lanigan, 2011, p. 399). Providers of family child care homes need to have support and professional development that is specific to family child care, the setting, the environment, and the demographic to which they serve (Rusby, 2002). "To achieve maximum quality, regulation should occur in tandem with a relationship-based support and professional development system that is strengths-based, nonjudgmental and distinct from licensing" (Lanigan, 2011, p. 407).

The findings of the study suggest that higher education is related to better quality, and are consistent with past research. Family child care has been found to be of low quality and is associated with the caregiver's level of education and training (Burchinal et al., 2002; ClarkeStewart, Vandell et al., 2002; Lanigan, 2011; Raikes et al., 2005). The quality of care can be improved when providers have been educated in the field of child development. An overwhelming $60 \%$ of child care providers in the state of West Virginia have no training in providing care for children. Child care directors create the guidelines and expectations for quality in their centers. Homes where the director and teacher is the same person should still be meeting the minimal requirements for quality. Grubb (1993) found that compliance with minimal standards were higher when providers had at least a high school diploma or GED, when they attended ongoing training, were oriented with standards, and/or belonged to a professional organization (Grubb, 1993). 


\section{References}

Annie E. Casey Foundation, B. D. (2006). Family, friend, and neighbor care: Strengthening a critical resource to help young children succeed. 2006 KIDS COUNT Essay. Annie E. Casey Foundation.

Bollin, G. G., \& Whitehead, L. C. (1991, April). Family day care quality and parental satisfaction. Paper presented at the Annual Conference of the American Educational Research Association, Chicago, IL. Abstract retrieved from http://www.eric.ed.gov/contentdelivery/servlet/ERICServlet?accno=ED330477.

Bordin, J., Machida, S., \& Varnell, H. (2000). The relation of quality indicators to provider knowledge of child development in family child care homes. Child \& Youth Care Forum, 29(5), 323-341.

Burchinal, M., Howes, C., \& Kontos, S. (2002). Structural predictors of child care quality in child care homes. Early Childhood Research Quarterly, 17(1), 87.

Chang, C., Austin, A., \& Piercy, K. W. (2006). Provider management of child stress behavior in family day care facilities: Scaffolding for learning and development by developmentally appropriate practice. Journal of Genetic Psychology, 167(2), 159-177.

Clarke-Stewart, K., Vandell, D., Burchinal, M., O’Brien, M., \& McCartney, K. (2002). Do regulable features of child-care homes affect children’s development? Early Childhood Research Quarterly, 17(1), 52-86.

Cress, S. W. (1998). A focus on literacy in home day care (ED Report 426 805). Retrieved from Indiana University South Bend: http://www.eric.ed.gov/contentdelivery/servlet/ERICServlet?accno=ED426805. 
Cryer, D. (1999). Defining and assessing early childhood program quality. Annals of the American Academy of Political and Social Science, 563, 39-55.

Cryer, D., \& Phillipsen, L. (1997). Quality details: A close-up look at child care program strengths and weaknesses. Young Children, 52(5), 51-61.

DeBord, K., \& Sawyers, J. (1996). The effects of training on the quality of family child care for those associated with and not associated with professional child care organizations. Child \& Youth Care Forum, 25(1), 7-15.

Department of Education. (2011). Race to the top fund. Federal Register, 76(176), 56183-56188.

Dodge, D. T., Colker, L. J., \& Heroman, C. (2002). The Creative Curriculum[R] for Preschool. Fourth Edition. Washington D.C.: Teaching Strategies, Inc.

Downer, J., Sabol, T. J., \& Hamre, B. (2010). Teacher-child interactions in the classroom: Toward a theory of within- and cross-domain links to children's developmental outcomes. Early Education and Development, 21(5), 699-723.

Fiene, R. (1995). Utilizing a statewide training system to improve child day care quality. Child Welfare, 74(6), 1189-1201.

Fiene, R., \& Melnick, S. A. (1989). Program quality and licensure in day care centers and family day care homes (ED Report 314 185). Retrieved from ERIC: http://www.eric.ed.gov/contentdelivery/servlet/ERICServlet?accno=ED314185.

Fuller, B., Kagan, S., Loeb, S., \& Chang, Y. (2004). Child care quality: centers and home settings that serve poor families. Early Childhood Research Quarterly, 19(4), 505-527.

Grubb, P. D. (1993). The quality of regulated family day care homes and compliance with minimum standards. Child Welfare, 72(5), 461. 
Grubb, P. D. (1993). Caregiver competencies and noncompliance with minimum standards in family day care homes. Child Welfare, 72(4), 357-365.

Harms, T. (1992). Designing settings to support high-quality care. In B. Spodek \& O. Saracho (Eds.), Yearbook in Early Childhood Education (Issues in Child Care, Vol. 3, pp.169186). New York, NY: Teachers College Press.

Harms, T., \& Cryer, D. (2007). Video observations for the family child are environmental rating scale [Video Tape]. (Available from Teachers College Press, New York, NY 10027.

Harms, T., Cryer, D., \& Clifford, R. M. (2007). Family child care environmental rating scale revised edition. New York, NY: Teachers College Press.

Lanigan, J. D. (2011). Family child care providers’ perspectives regarding effective professional development and their role in the child care system: A qualitative study. Early Childhood Education Journal, 38(6), 399-409.

Liu, M., Anderson, S. G. (2010). Understanding caregiving patterns, motivations, and resource needs of subsidized family, friend, and neighbor child care providers. Child Welfare, 89(3), 99.

Loeb, S., Fuller, B., Kagan, S., \& Carrol, B. (2004). Child Care in Poor Communities: Early Learning Effects of Type, Quality, and Stability. Child Development, 75(1), 47-65.

Lowman, L, H., \& Ruhmann, L. H. (1998). Simply sensational spaces: A multi-“s” approach to toddler environments. Young Children, 53(3), 11-17.

Moore, G. T. (1994). The developmentally appropriate design of child care facilities. Morrissey, T.W. (2007). Family child care in the United States. Child Care \& Early Education Research Connections. Retrieved from http://www.researchconnections.org/childcare/resources/11683/pdf. 
National Child Care Information and Technical Assistance Center. (2007). Definition of licensed family child care homes. Retrieved from http://nccic.acf.hhs.gov/pubs/cclicensingreq/definition-fcc.html.

NICHD Early Child Care Research Network and Duncan, G. J. (2003). Modeling the impacts of child care quality on children's preschool cognitive development. Child development, 74(5), 1454-1475.

Norris, D. J. (2001). Quality of care offered by providers with differential patterns of workshop participation. Child \& Youth Care Forum, 30(2), 111-121.

Ostrosky, M. M., Jung, E. Y., Hemmeter, M. L., \& Thomas, D. D. (2003). Helping Children Understand Routines and Classroom Schedules. What Works Briefs.

Partnership for America’s Economic Success. (2011). Paying later: The high costs of failing to invest in young children. The PEW Center on the States. Retrieved from http://www.pewcenteronthestats.org.

Raikes, H., Raikes, H. H., \& Wilcox, B. (2005). Regulation, subsidy receipt and provider characteristics: What predicts quality in child care homes? Early Childhood Research Quarterly, 20(2), 164-184.

Rusby, J. (2002). Training needs and challenges of family child care providers. Child \& Youth Care Forum, 31(5), 281-293.

Shallcross, M. A. (1995). Improving the safety standards of family child care homes by developing and implementing a health and safety training program for state-licensed family child care providers (ED Report 393 583). Retrieved from Nova Southeastern University: http://www.eric.ed.gov/contentdelivery/servlet/ERICServlet?accno=ED393583. 
Shivers, E. (2006). A closer look at kith and kin care: Exploring variability of quality within family, friend and neighbor care. Journal of Applied Developmental Psychology, 27(5), 411-426.

Thomason, A. C., \& La Paro, K. M. (2009). Measuring the quality of teacher-child interactions in toddler child care. Early Education and Development, 20(2), 285-304.

Trost, S. G., Messner, L. L., Fitzgerald, K. K., \& Roths, B. B. (2009). Nutrition and physical activity policies and practices in family child care homes. American Journal of Preventive Medicine, 37(6), 537-540.

Walker, S. K. (2002). Predictor's of family child care providers' intentions toward professional development. Child \& Youth Care Forum, 31(4), 215-231.

West Virginia Department of Health and Human Resources Legislative Rules. (2007). Family child care home licensing requirements. Title 78, Series 19.

West Virginia Department of Health and Human Resources Legislative Rules. (2007). Family child care facility licensing requirements. Title 78, Series 18.

West Virginia Department of Health and Human Resources. (2011). Tiered reimbursement for child care subsidy program. Retrieved from http://www.wvdhhr.org/bcf/ece/earlycare/tiered_reimb.asp.

Wilkes, D. L., Lambert, R., \& VandeWiele, L. (1998). Technical assistance as part of routine inspections of family child care homes. Early Childhood Research Quarterly, 13(2), 35572. 
Appendix

Anecdotal Notes

Anecdotal notes and comments were also collected by the observer/trainers and observers in child care settings. For qualitative purposes, included are some of their comments.

Comments from the two lowest subscales:

Personal Care Routines

7. Greeting/departing:

- Children come and go as they please. Children walk home alone.

8. Nap/rest:

- Kids sleep on couch and mattress together.

- Provider doesn't use cots. Children fall asleep on their own and are put on the couch.

- Child fell asleep in swing and was left there.

- Child was not supervised while sleeping.

- Bedding should not touch other bedding for sanitary purposes.

- $\quad$ Cots are too close together.

- Sleeping on the couch is not personal or sanitary.

- Baby was asleep on stomach.

- Children share a crib, but not at the same time.

- There were toys in cribs and pack n plays so child slept on couch.

- Baby sleeping in a crowded, noisy room.

- Bedding should be washed weekly.

9. Meals/snacks

- Adults did not wash hands before preparation or after feeding. Cookie fell on floor and was placed back in bowl for child to eat.

- Children do not wash hands or clean table before or after eating. 
- Tables/highchair trays were not washed or sanitized before or after eating. Children and adults did not wash hands before or after.

- Child uses hand sanitizer in infant room.

- Children ate on the floor.

- Children’s hands not washed properly or re-contaminated.

- $\quad$ Sippy cups were carried around and children ate while standing and moving.

- Teacher didn't wash hands or use gloves when handling food. It took forever to give them drinks. Children lay sippy cups on floor.

10. Diapering/toileting

- Trashcan was set on couch and had no lid. Children's hands not washed. No paper towels/hand towels. Changing table not sanitized.

- Children go to bathroom, but child did not wash hands.

- Changed child with disabilities on the floor.

- $\quad$ Sink not sanitized.

- Paper towels should be used instead of hand towels.

- Adult supervision needed.

- Unclean diapering area.

- No prep, proper disposal, children's hands not wiped, diaper area not cleaned, no sanitization.

- No hand washing, sanitation, proper disposal, wiping of hands, cleaning of diaper area.

- No proper disposal, children's hands not wiped, diaper area not cleaned or sanitized, sink not sanitized.

- Provider didn’t wash hands between children, didn’t dispose properly, did not clean diaper area.

- $\quad$ Provider used floor to diaper and did not follow diapering procedure.

- Child changed on floor where kids play.

- Children use same water bowl to wash hands.

- Child changed on bed. 
- No hands-free trash can.

- No hand washing after using the bathroom or supervision of children.

11. Health practices

- Helper has pneumonia. One child coughing another runny nose. Hand towel used in restroom. Toothbrushes stored touching in cup. Children and adults did not wash hands upon arrival or re-entry or after dealing with bodily fluids.

- Hands were not washed upon arrival or reentry, after dealing with bodily fluids, or after touching pets or contaminated objects.

- Children did not wash hands after messy sand or water play.

- Cigarettes in reach of children.

- Children going inside and out and one child came out of bathroom and was not asked if he washed his hands.

- Cat on counter with drinks/food. Children were sharing a horn.

- Smoking at the door.

- Child had finger in nose and did not wash hands.

- The floors were dirty.

- Dirty pacifier was used and children use a bowl to wash hands.

- Child sneezed and didn’t wash hands.

- Smoke on outside porch.

12. Safety practices

- Medicine on counter, unprotected wall heater, glass globes on shelves.

- No outdoor playground, bunk bed, toys in crowded area, swing set not fenced in.

- $\quad$ Steps to go outside are a hazard.

- No covered outlets, deep-freeze, cords, breakable items, no fenced in area.

- No gate for stairs. Slide too high.

- Children sat on ledge for snack. Too many swings close together outside-fall zone.

- Cement blocks, slide, grill, mulch, and fall zone. 
- Indoor brick fire place, staircase dangerous, leave children unsupervised. Outdoor metal pole, sandbox unsanitary, and area is unfenced.

- Provider leaves kids inside while outside.

- $\quad$ Play equipment not sturdy.

- Entrapment in the fence, uncapped bolts, and rusty gate.

- Indoor breakable vase; outdoor not enough fall zone space for swings, exit zone too short on slide.

- Seats high without extra assistance. No outdoor fencing, no mulch, fall depth.

- Breakable items in children's reach.

- Objects could fall and hit children sleeping if storage crib gets bumped.

- Open fencing to street.

- Cord hanging where heavy object could be pulled.

- Sharp wire in fencing. Pinching hazards with door.

- Rusty fencing, entrapment, sharp wood corners, cushioning, exit regions, drop off porch, swing pivot points.

- Gas can by sandbox, entrapment, lawnmower, child left on stairs alone.

- Children climbing over shelves, children sit on stacked chairs. Children walk from house to another building alone beside main road with no fence.

- Vacuum with cord and lawnmower.

- Cat litter and mop in open room.

- Medicine left out, swing set not sturdy, unsafe riding toys.

- Indoor hazards include medicine not locked up (under crib), screw/nail bucket in reach, cord/plugs exposed, plugs uncovered, tin can lids in open trash, heavy objects that can be pulled down, knife left out. Outdoor hazards include pinching hazards, entrapment, nails laying out, not enough fall zones, no exit region on slide, not enough pivot regions, no cushioning.

- $\quad$ No supervision of pool.

- Outdoor trampoline is a hazard.

- Outdoor play near and on edge of road. 
Activities

16. Fine Motor

- $\quad$ Fine motor toys should be organized.

- Nothing accessible, stored in bedrooms.

- Most toys in tubs stacked on top of each other.

- $\quad$ Need more infant and toddler toys.

- $\quad$ Need more accessibility.

- No building toys or puzzles.

- No building toys or manipulatives.

- Not a large variety.

- Not enough materials for each age group.

- Provider does not interact.

17. Art

- Only do crafts in winter, colored doorknob hangers.

- $\quad$ Toddlers need to do art.

- No art work, no art materials accessible or displayed.

- No materials for toddlers.

- No 3-D art or collage materials or tools for art.

- $\quad$ Spray paint is dangerous.

- No paint.

- No art visible, sidewalk chalk once in a while.

- Older children do not do art activities, they have movie time and if they wanted to it's not accessible.

- Had art area but shelves and baby gates blocked it.

- Children scribble with no direction.

- Small beads are unsafe. 
- Art is not a daily occurrence.

18. Music and movement

- No activities planned, no informal singing observed.

- No music or informal singing observed, if there are musical toys they are in bedroom.

- No music.

- Need music materials.

- Country Music Television was on all day.

- Not enough music toys accessible to children.

- Recorded music plays when children are interested.

- No music at nap. No recorded music or informal singing.

- No musical instruments or musical toys, no informal singing or recorded music.

19. Blocks

- Tub of accessories, but no blocks.

- Blocks in bedroom but not free space.

- One homemade block available.

- No clear floor space for block play.

- No accessories near blocks.

- Provider does not encourage or participate in block play.

- No sets of blocks.

- Very few blocks.

- Block rug in area of high traffic.

20. Dramatic play

- Accessible to older kids but not younger, girl toys needed, should have toys for infants.

- None in infant room.

- No diversity or provider facilitated play.

- Not enough toys for each age group. 
- Baby dolls not accessible.

- No clothes, limited food.

21. Math/number

- No math.

- Provider does not talk about math.

- Not enough math materials.

- Need more variety.

22. Nature/science

- No collection of natural objects, living things, tools, books, pictures, games, or toys.

- Some books but had to search for them.

- Don't go outside or have nature books.

- Need more materials.

- No nature/science tools or materials for infants.

- No living things or tools.

- Does not use living things and plants.

- Not available all the time, no collections.

- Provider does not use every day experiences to talk about science.

23. Sand and water play

- None observed and when interviewed does not provide any.

- No sand or water inside.

- Outdoor sandbox only, but close due to cat poop.

- Water slide doesn’t count.

- None.

- Sprinkler once in a while. They wash the dog.

- Sand box with rocks, water table (pool) very crowded. No toys outdoors for sand or water, just buckets. 
- No specific activities.

- Outdoor water, a couple times a week in summer only.

24. Promoting acceptance of diversity

- Not a lot of pictures.

- No books represent disabilities.

- Pictures and materials do not represent all aspects of diversity.

- No diverse materials.

- No materials representing age or ability.

- White baby only, no books, no pictures of ability, no materials of age or ability.

- No pictures to represent abilities, no materials for race/culture or abilities.

- All babies one race.

- Not enough materials for each area.

- No materials representing abilities or gender.

25. Use of TV, video, and/or computer

- TV on almost all day.

- TV on the entire day.

- TV on during the entire observation.

- TV on most of the time in infant room, TV for children under 12 months is not appropriate.

- Children play video games.

- Children have no limit on TV including Nickelodeon, Disney, and cartoons.

- Watch TV during bad weather or winter.

- Watch SpongeBob.

- Watch Shrek.

- Watched Lord of the Rings.

- Inappropriate-kidnapping. 
- Violence in many Disney movies.

- Violent video games.

- Watched Jack, TV on mute entire time.

- TV on during observation, children come and go, TV was very loud.

- Lots of violent games and none educational, hunting, Mario Kart, gun games.

- Wii Guitar Hero, each child uses TV about 30 minutes each for games but there is no limit.

- TV time open for most of time or any time they want, movie avatar, TV on all day, Wii.

- TV not limited but educational, TV on entire observation.

- Inappropriate movies, Goonies and Mouse Hunt.

- Games not really limited.

26. Active physical play

- Area not fenced in.

- Unsafe equipment.

- Not a lot of toys outside. Area not fenced in.

- Children under 2 do not go outside.

- Equipment/materials inappropriate or unsafe, indoor/outdoor space used inappropriately.

- Pool cannot be considered active play.

- Gate unsafe, sufficient cushioning is not there, no padding for children, no play material for younger infants.

- Outside not fenced, very wet, no mulch/cushioning.

- Swings too close, cushioning, tire swing, fall zones, uncapped bolts, entrapment, tripping, and steps.

- Close to street.

- Front porch has no cushioning to protect children from a tough or hard fall, not really any equipment for active physical play.

- The children were playing around household items that were not safe and the stairs, a gate was open. 
- Not fenced in at bike area and nothing for the 8 year old to play with.

- Outdoor not safe.

- The Wii is inappropriate.

- Unsafe area outside, materials outside are in poor repair.

- No cushioning, open gate to street.

- Not fenced in, high grass at edges, bugs, not enough for fall zone, no cushioning.

- Not accessible for disabilities, no ample play materials.

Interaction

27. Supervision of play and learning

- Children allowed to finish art activity before going to another station.

- Provider does a great job of supervising children.

- 2 teachers 1 for smaller children and 1 for older children.

- One staff member outside, one staff member inside at all times with children.

- Made up a game and explained rules.

- Supervision of all children majority of time.

28. Provider-child interaction

- Talks to children about how well they are sharing and putting toys back, hugs children when crying or did something they were asked.

- Hugs child when child falls down and comforts and explains it's okay.

- Positive verbal interaction with all children. Infant child/teacher repeats what he says then says something very patient and talks to each child, physical interaction always comforting and interacting with children.

- Verbally talking to children calmly about reading a book before naptime, physically holding infant and hugging toddler.

- Encourages individual art.

- Staff asks child if he would like to get a puzzle down because he sees child looking and reaching. Staff walks over and helps child get puzzle and high fives child.

- Appreciative of children’s accomplishments. 
- Good verbal and nonverbal interactions.

- Helps children when upset.

- Children love her and don’t want to go home.

- Provider has pleasant voice.

29. Discipline

- Provider redirected children and explained why they were corrected.

- Redirects when she does something wrong instead of punishing.

- Timeout is used.

- Redirects children.

- Time out used and then discussed.

- Provider explained to child why you have to share.

- Redirection to children, explains what they did wrong.

30. Interaction among children

- Provider talks about 2 children playing nice together in the block area, involved in dramatic play, helped children work/play together.

- Group art activity promoted.

- Provider told the group of boys how good of a job they were doing playing and working together, put things out that encouraged children to work together to make or complete it.

- Provider initiated activities for children to work together art activity, puzzle, and air hockey.

- Provider initiated art activity, music and dancing.

- Children playing cards together nicely.

- Provider encouraged children to work or play together through painting an owl puzzle.

- Encourages younger children to come to table and color with kids.

- Children encouraged to work play together and praised.

- Clean up together.

- Thanks older kids for helping, organized game for children. 
- Children held hands while dancing, and found a binky for the baby.

- Encourages and praised children for playing together.

- Children build castle together.

- Children fold clothes together.

- Played with play-doh as a group.

- Singing and sharing together during free play.

- Children sharing and picking leaves together.

- Points out and encourages children interaction with one another.

- Encourages children to communicate with one another.

- Older child read to younger one.

Listening and Talking

13. Helping children understand language

- Children talk about days of the week, fall, songs, provider pretends with children during dramatic play and block play.

- Talking to children about what is coming after snack (drinks), if they wanted to go outside, talking to them about the bingo song, descriptive words used by infant teacher.

- Talked about math.

- Talked during routines, free play, and used descriptive words about temperature.

- Talks during play by helping children with computer game.

- Used sign language, interacted and asked questions during every book, talked during play and routines, used descriptive words.

- Explained rules during routines.

14. Helping children use language

- Encourages use of inside voice.

- Children communicate during dramatic play while shopping for food and in block play by building together. Provider talks to infants about not being scared, provider hugs children when crying.

- Children encouraged to communicate with one another during homework and dinner. 
- Children encouraged to communicate with each other at snack and free play.

- Children encouraged to communicate with each other by building a house together and having a tea party.

- Art craft laid out and group time to encourage communication between children.

- Children communicate with each other through an art project and a music tape on TV.

- Interactions through messy play and a group owl puzzle.

- Provider had good verbal and nonverbal responses, encouraged children to communicate with one another through a game and dramatic play.

- Nonverbal responses and children encouraged to communicate with one another at snack time, group activities, and clean up.

- Encourages children to communicate by playing a game and learning letters.

- Children encouraged to communicate with one another setting up cleaning up playing together.

- Children encouraged to communicate with one another through reading and outside games.

15. Using books

- Books of race, age, abilities, animals, familiar experiences, fiction and factual. Provider read to individuals and small groups in both pre $\mathrm{k}$ and toddler classes at story time.

- Wide selection of books for all age groups in all categories, provider reads to individuals and small groups during morning story and free play and encourages children to read at their ability level.

- Provider has reading time daily.

- Wide selection of books, many for each age group, none inappropriate or in disrepair.

- 4 shelves of books in all selected categories.

- Wide selection, provider reads to children, no inappropriate books.

- Plenty of books, read to children.

- Wide selection and a reading corner where provider read to children.

- Many books, read to children at circle time and free play.

- Wide variety of books, provider read to children at free play, story time and provider encourages children to read. 
- Many books, provider read to children and encouraged reading.

- Variety of books, children read nursery rhyme.

- Provider reads to children before nap and during free time.

- Used math and science during reading.

- Provider read veggie tales to kids, provider encourages older kids to read.

Program Structure

31. Schedule

- Schedule familiar to children.

- Timer used for transitions.

- Children used to schedule.

- Nap times and meals about the same time every day.

32. Free play

- Story time was supervision used as education interaction.

- Most of the day is scheduled activity.

- Older kids learn letters.

- Provider reads to children and children read to others.

- Child asked if they could draw a treble clef as an example of supervision used to educate.

- Practiced vocabulary words and counting with play-doh.

- Talked about different types of food.

- Takes child places, learned to play drums.

- Children learn shapes and colors.

33. Group time

- Art done in small groups, story time, whole group time broke into 2 different times.

- Circle time, baby can read, abc time, exercise time

- Read books and learned the alphabet

- Reading and crafts 
- Teaching letters

- Small group interactions included rhyming and nature questions

- Interaction with small group to talk about story shapes and colors

- Learned left from right

34. Provisions for children with disabilities

- Child with speech, birth to 3 services, provider helps any way needed with parents and birth to 3 .

- $\quad$ Provider makes home visits, talks to parents, meetings with parents.

- Discusses problems

- Keeps noise level down 